\title{
Dificuldades e Estratégias para Compreensão do Conceito de Emaranhamento Quântico: Um Estudo na Formação Inicial de Professores de Física
}

\author{
Difficulties and Strategies in Understanding the Concept of \\ Quantum Entanglement: A Study ith Pre-service Physics \\ Teachers
}

\author{
Jader da Silva Netto \\ Cláudio José de Holanda Cavalcanti \\ Brasil \\ Fernanda Ostermann \\ Brasil \\ Brasil
}

Este trabalho apresenta os resultados de uma pesquisa de doutorado envolvendo o estudo do emaranhamento quântico na disciplina de Física Moderna e Contemporânea de um curso de Licenciatura em Física. O marco teórico-metodológico adotado foi a teoria da mediação de Vygotsky e a filosofia linguística de Bakhtin. A partir da simulação computacional do emaranhamento quântico no Interferômetro Virtual de MachZehnder e considerando uma abordagem fenomenológica, buscou-se compreender quais são os recursos utilizados e as dificuldades enfrentadas pelos futuros professores ao propor uma explicação para o fenômeno. Os estudantes trabalharam em duplas, utilizando um roteiro exploratório e as interações discursivas resultantes foram gravadas em áudio para posterior transcrição e análise. Os resultados obtidos mostram que, frente ao caráter bastante contraintuitivo do fenômeno, os estudantes acabam recorrendo a modelos clássicos que dificultam o reconhecimento do caráter não local, fundamental para a compreensão do emaranhamento quântico. Além disso, o resultados evidenciam o papel do software e do roteiro exploratório como ferramentas mediadoras, uma vez que promovem ricas trocas discursivas entre os estudantes, as quais são fundamentais para que consigam prosseguir na atividade.

Palavras-chave: emaranhamento quântico; formação de professores; Interferômetro Virtual de Mach-Zehnder.

This paper presents the results of a $\mathrm{PhD}$ research about the study of quantum entanglement in a Modern and Contemporary Physics course involving pre-service physics teachers. The theoretical and methodological framework adopted in this research is the Vygotsky's theory of mediation and Bakhtin's linguistics philosophy. From the computational simulation of quantum entanglement in Mach-Zehnder Virtual Interferometer and 
taking a phenomenological approach, we tried to understand what are the strategies used and the difficulties encountered by the future teachers in proposing an explanation for the phenomenon. The students worked in pairs using an exploratory guide and the discursive interactions were audio recorded for later transcription and analysis. The results show that given the rather counterintuitive character of the phenomenon, students end up using classical models that make it difficult to recognize the nonlocality, a fundamental pre-requisite for the understanding of quantum entanglement. In addition, the results highlight the role of software and exploratory guide as mediating tools since they promote valuable discursive exchanges between students, which are determinant for them to be able to continue the activity.

Keywords: quantum entanglement; pre-service teachers; Virtual Mach-Zehnder Interferometer.

\section{Introdução}

A formação inicial e continuada de professores é um tema bastante abrangente, uma vez que envolve diversos aspectos, como modelos de formação, desinteressecrescente pelo ingresso em cursos de licenciatura, políticas públicas de formação de professores (que, entre muitos objetivos, visam despertar o interesse pela profissão docente e suprir uma demanda crescente), saberes docentes, diretrizes curriculares, entre tantos outros. A discussão de cada um desses elementos intervenientes não é recente e a produção acadêmica nessa área é vasta. Inseridos nesse contexto da formação de professores, nossa discussão está relacionada às questões de currículo e aprendizagem de conceitos.

A referência que um professor recém-formado tem em relação a metodologias e conteúdos propriamente é aquela com a qual teve contato durante sua formação. Assim, seja para manutenção ou transformação do contexto escolar com o qual se depara, é natural que acabe incorporando elementos da sua formação na prática escolar. Além disso, enquanto parte da cultura escolar, o livro didático apresenta-se como uma das principais ferramentas de apoio do professor. No caso da discussão que realizamos nesse trabalho, esses aspectos têm particular importância.

O objeto de estudo nesse trabalho é a formação inicial do professor de Física. Nossa preocupação é quanto à formação em relação a temas de Física Moderna e Contemporânea (FMC), dialogando com outros trabalhos que se inserem nessa mesma linha de pesquisa, iniciada no Brasil nos anos 1990 (Freire Jr. et al., 1995; Ostermann, 1999; Ostermann, \& Cavalcanti, 1999; Ostermann, \& Moreira, 2000; Pinto, \& Zanetic, 1999; Terrazzan, 1992, 1994). Nesse contexto, aspectos ligados à abordagem da Física Quântica (FQ) no ensino de graduação e estruturação de conteúdos da FMC nos livros didáticos de Física do Ensino Médio são dois elementos que merecem atenção. Este trabalho se concentra no primeiro.

A literatura na área aponta que os livros didáticos praticamente não abordam conceitos fundamentais de FQ, ficando restritos ao que é conhecido como a velha FQ (Dominguini, Maximiano, \& Cardoso, 2012). Enquanto os livros didáticos de Física 
utilizados no Brasil no início do século XX traziam temas de uma ciência que estava acontecendo (Martins, 2015), explorando, por exemplo, temas ligados à radioatividade e ao uso dos raios $\mathrm{X}$ na Medicina, o mesmo não se pode dizer em relação aos livros didáticos de hoje. Isso denota um grande descompasso entre aquilo que os estudantes querem saber e o que a escola e o professor têm condições de oferecer. $\mathrm{O}$ caráter de artefato cultural do livro obviamente permanece, assim como da ciência, entretanto, a transposição didática permanece atrelada a uma série de conteúdos que ficaram restritos à Física Clássica e à Física do início do século passado.

A defasagem do livro didático em relação a temas de FQ não é o único motivo para que esta não seja abordada no Ensino Médio. É preciso considerar também a percepção do professor sobre esses temas. De modo geral, por explorar sistemas físicos que apresentam comportamento contraintuitivo, que não pode ser descrito pela Física Clássica, a FQ é considerada uma área de estudos complexa tanto em seu aspecto formal quanto conceitual. Os próprios espaços de formação docente, onde esta percepção poderia ser evitada, muitas vezes acabam reforçando-a. Isso ocorre especialmente a partir de abordagens da FQ centradas em sua formulação matemática com raros momentos onde o seu formalismo se relaciona com os aspectos conceituais da teoria. A supervalorização de procedimentos matemáticos, inevitavelmente acaba promovendo um distanciamento da FQ em relação aos seus conceitos e sua conexão com resultados experimentais e interpretações (Johansson, Andersson, Salminen-Karlsson, \& Elmgren, 2016). Dessa forma, é natural que seja taxada como complicada e sem conexão com o mundo real. Uma vez atuando no Ensino Médio, os professores não se sentirão capazes de explorar a FQ, pois não a compreendem.

A pesquisa em ensino de Física tem se dedicado nos últimos anos a explorar a formação docente em FQ, utilizando basicamente estratégias que envolvem o uso de recursos computacionais (Netto, 2015). É nesse cenário que se insere esta pesquisa. Busca-se compreender, no processo de formação docente, em que medida uma ferramenta computacional contribui para a compreensão de conceitos de FQ e quais são as estratégias utilizadas pelos estudantes nesse processo. Nessa perspectiva, alguns resultados de pesquisa já foram apresentados anteriormente, quando exploramos a complementaridade onda-partícula (Netto, Cavalcanti, \& Ostermann, 2015). Este trabalho envolve o estudo do fenômeno do emaranhamento quântico com professores em formação.

Ao propor o estudo do emaranhamento quântico, é necessário tratar a compreensão do fenômeno tomando inicialmente o contexto no qual se deram as reflexões teóricas propostas por Einstein, Podolsky e Rosen (Einstein, Podolsky, \& Rosen, 1935) e promover seu reconhecimento como campo de investigação consolidado na Física. Esses fatos se inserem em uma cadeia complexa e repleta de sutilezas, se estendendo entre a metade da década de 30 e a primeira metade da década de 80 (Freire Jr, 2006), produzindo intensos debates até os dias atuais.

O emaranhamento quântico, apesar da sua atualidade, é pouco discutido nos 
cursos de formação de professores de Física. A importância do seu estudo recai não apenas nas suas aplicações tecnológicas, mas sobretudo nas possibilidades que oferece para compreensão do desenvolvimento da teoria quântica, seja em relação aos seus fundamentos ou aos pressupostos filosóficos e epistemológicos e suas implicações. Esses são aspectos fundamentais quando se defende um ensino de Física que proporcione uma imagem de ciência como processo em construção por seres humanos e com um caráter altamente interdisciplinar. Um ensino pautado apenas na mera enumeração da utilidade ou possibilidade de aplicação tecnológica dos conhecimentos científicos pode facilmente recair no modismo do ensino do cotidiano ${ }^{1}$ e desconsiderar outras questões mais importantes. Os elementos aqui elencados vêm ao encontro da necessidade de se investir em uma melhor formação do professor. Se, por um lado, existe todo um movimento que defende a inserção de tópicos de FMC no currículo escolar do Ensino Médio, é necessário também um olhar para a formação do professor de Física. Sem dúvida, a efetiva abordagem de tais tópicos nesse nível de ensino depende de uma formação mais sólida e atual do professor (Ostermann, \& Prado, 2005).

Como parte dos resultados das pesquisas do nosso grupo, desenvolveu-se um software que possibilita explorar conceitos da FQ com base na simulação computacional. Trata-se do Interferômetro Virtual de Mach-Zehnder (IVMZ), já apresentado em trabalho anterior (Netto et al., 2015).

Neste trabalho, apresentamos os resultados de uma pesquisa realizada com alunos de Licenciatura em Física, em que o emaranhamento quântico foi estudado numa perspectiva fenomenológica e conceitual a partir de uma simulação computacional no IVMZ. Nosso objetivo é investigar as estratégias utilizadas e dificuldades encontradas pelos estudantes na busca por uma explicação para o fenômeno em estudo, assim como o papel exercido pelo software nesse processo.

\section{Referencial teórico-metodológico}

Segundo a perspectiva sociocultural, o processo de compreensão ocorre de maneira dialógica, uma vez que requer intercâmbio de ideias. Nessa relação dinâmica, a linguagem assume o papel de principal ferramenta mediadora. A fim de promover uma análise que seja capaz de integrar a aprendizagem de conceitos com o uso de ferramentas mediadoras, recorremos à teoria da mediação de Vygotsky e à filosofia linguística de Bakhtin.

A teoria psicológica de Vygotsky é considerada a precursora da perspectiva sociocultural e se preocupa, entre outras coisas, em compreender de que modo o domínio de formas socioculturalmente situadas de ação mediada (no plano interpsicológico) pode levar a formas mais particulares das mesmas no plano intrapsicológico (Wertsch, 1993).

\footnotetext{
$1 \mathrm{O}$ termo cotidiano é normalmente entendido como o contexto vivencial mais direto do aluno (suas experiências e vivências diárias, comumente denominadas dia-a-dia). Isso implica um tipo de ensino que deve ser evitado por ser reducionista, limitado e enciclopédico (Santos, \& Mortimer, 2000).
} 
De modo geral, isso caracteriza o processo de desenvolvimento psicológico, que pode ser caracterizado por uma evolução qualitativa na capacidade de realizar certas tarefas de um nível de complexidade para outro mais elevado. Isso remete ao conceito de Zona de Desenvolvimento Proximal (ZDP), definido como a distância entre os níveis de desenvolvimento real e potencial (Vygotsky, 1994).

Existem concepções errôneas tanto em relação à interpretação da ZDP quando da zona de desenvolvimento potencial de um aprendiz (Chaiklin, 2003). Persiste a crença de que a primeira pode ser identificada de forma adequada para cada atividade e de que a segunda é uma propriedade do aprendiz quando, na verdade, representa um indicativo da presença de funções de maturação. Isso conduz a uma simplificação segundo a qual estas zonas de desenvolvimento são bem determinadas e que bastaria identificá-las para se obter a chave para os processos de aprendizagem. Diferente disso, o autor propõe que é a presença das funções de maturação o aspecto relevante no processo de aprendizagem, o que implica dizer que a ZDP está relacionada com o desenvolvimento em si e não com tarefas específicas. Além disso, tomando o cenário da ação colaborativa entre indivíduos é preciso analisar mais detalhadamente como a assistência de um parceiro mais capaz atua na criação de uma ZDP, evitando assim imprecisões em torno desse conceito. Essa assistência pode ocorrer de formas distintas para vários aprendizes, possibilitando que estes, mesmo em condições diversas, tenham sucesso na resolução de um dado problema. Analisar apenas o sucesso em resolver uma tarefa permitiria afirmar, de modo equivocado, que esses estão no mesmo nível de desenvolvimento proximal.

A fim de promover um entendimento mais profundo sobre a ZDP, Wertsch propõe uma interpretação baseada em três conceitos: definição de situação, intersubjetividade e mediação semiótica (Wertsch, 1984).

Definição de situação se refere à representação de um contexto espaço-temporal que é criado pelos indivíduos que nele atuam. No cenário envolvendo trabalho em grupos, como no caso de um adulto e uma criança, a representação que estes têm dos eventos e objetos se dá de formas distintas. Isso implica dizer que apesar de atuarem de forma colaborativa, ambos não realizam a mesma tarefa. Embora venham a ser executadas as mesmas ações, pode haver fatores bastante distintos que motivam as ações de ambos, isto é, estão envolvidos padrões de ação diversos. Nesse caso, para um dos interlocutores assumir uma definição de situação como a do outro é necessário a reconstrução completa da definição de situação. Essa mudança não étrivial. Pelo contrário, é profunda e de natureza qualitativa, uma vez que não se trata apenas de um acréscimo de conhecimento. Trata-se de uma mudança radical na forma de representar objetos e eventos pertencentes a esse cenário, ou seja, é necessário criar um novo padrão de ações.

Quando, em uma tarefa, dois interlocutores compartilham, e sabem que compartilham, a mesma definição de situação estabelece-se a intersubjetividade. A intersubjetividade pode ocorrer em vários níveis, desde o simples acordo entre os interlocutores até processos mais completos em que ambos têm representações idênticas para os objetos e eventos. $\mathrm{Na}$ maioria dos casos, entretanto, a intersubjetividade se 
estabelece em um termo intermediário no qual a definição de situação intersubjetiva é negociada. Essa negociação somente se torna possível a partir da mediação semiótica, que pode ocorrer pelo uso da linguagem, por exemplo (Wertsch, 1984). As várias possibilidades de negociação podem aparecer sob a forma de enunciados variados, sejam eles diretivos (um interlocutor atribui tarefas ao outro tomando um padrão de ações condizente com sua definição de situação) ou mais 'consultivos' (um interlocutor procura fornecer meios para que o outro modifique sua representação dos objetos e padrões de ação). Este segundo caso indica um tipo de flexibilidade semiótica que soa como um convite ao interlocutor para promover uma nova definição de situação, representando objetos e eventos num novo nível de intersubjetividade. Roteiros e textos explicativos podem ser articulados nesse processo. Quando se toma o contexto da sala de aula, a fala assume um papel de grande relevância no processo de negociação da definição de situação.

Esse processo de negociação, que se estabelece com base no uso de ferramentas mediadoras, quando analisado sob uma perspectiva ontogenética conduz à noção de internalização, que pode ser interpretada de duas formas: como domínio e como apropriação (Wertsch, 1998). A noção de domínio, diz respeito a saber como utilizar uma ferramenta cultural e requer a compreensão dos significados dos signos. O domínio de uma língua, por exemplo, implica reconhecer os seus códigos e regras e saber utilizálos de modo seguro. Já a apropriação das ferramentas culturais é mais abrangente e diz respeito a tornar próprio. A apropriação da língua implica tomar para si as palavras dos outros, povoando-as com acentos e intenções discursivas próprias (Bakhtin, 1981). A apropriação de uma ferramenta cultural exige o estabelecimento de uma íntima e profunda relação entre esta e o indivíduo que a utiliza. É isso que torna possível a utilização dos sistemas de signos nos mais diferentes contextos e com finalidades variadas. Trata-se de um processo que, quando ocorre, envolve um longo prazo, pois requer a remodelagem de um sistema de signos, algo bastante complexo.

No contexto da pesquisa realizada, analisar o domínio e apropriação de artefatos culturais, como o software, e dos conceitos envolvidos pode fornecer indícios sobre o processo de aprendizagem dos estudantes. Quando se toma o contexto sociocultural representado pela sala de aula (professor, estudantes e a cadeia de relações que se estabelecem) a perspectiva bakhtiniana da linguagem se torna um referencial valioso.

Considerando as condições sociais em que se dá o uso da linguagem em sala de aula, ou seja, um cenário propício à interação entre indivíduos que se constituem de diferentes contextos sociais, históricos e culturais, o conteúdo ideológico presente em seus enunciados acaba por delimitar espaços de disputa. Isso significa que nenhum enunciado é neutro, nem indiferente ao outro, o que deixa claro o papel que assumem como elos no processo discursivo (Bakhtin, 2011). Esse aspecto se refere a um dos pilares do pensamento bakhtiniano, o dialogismo.

O enunciado, na concepção bakhtiniana, se constitui, entre outros aspectos, de um contexto extraverbal, que identifica o caráter social da linguagem, de modo que este 
pode ser compreendido como o contexto ou o momento sócio-histórico-cultural em que os interlocutores se situam. Assim, o enunciado é capaz de avançar para além da sua materialidade, estando carregado de mensagens implícitas, que podem pertencer tanto a um contexto social imediato quanto a contextos mais amplos.

Isso implica o aparecimento de vozes discursivas que moldam o discurso e que, muitas vezes, podem não ser exatamente a dos interlocutores (interanimação de vozes), mas pertencer a discursos produzidos em outros espaços e épocas, ou seja, a outros contextos socioculturais. Enunciado e vozes discursivas formam um todo inseparável (Wertsch, 1993) e revelam a intencionalidade dos interlocutores. Uma vez que a linguagem é o produto vivo da interação social, das condições materiais e históricas de cada tempo, a compreensão de um enunciado é um processo dinâmico que não se restringe a decodificar a mensagem que carrega. Por mais que um enunciado carregue uma mensagem específica, seu significado pode não ser o mesmo para diferentes interlocutores. Nesse processo de compreensão de um enunciado ocorre a sua reelaboração a partir de recursos linguísticos próprios, ou seja, se caracteriza pelo emprego de palavras e entonações particulares. Na perspectiva bakhtiniana, se diz que ocorre a associação de contrapalavras que buscam ressignificar o discurso (Bakhtin, 2009).

A associação de contrapalavras é uma estratégia bastante poderosa para análise discursiva, uma vez que a diversidade dessas e o seu caráter ideológico permitem revelar crenças, valores, vozes discursivas e, até mesmo, a incompreensão do enunciado. Esse tipo de análise possibilita ao pesquisador certificar-se de quais são os significados que estão em jogo e como estes são articulados, podendo evidenciar o processo de domínio ou apropriação das ferramentas culturais envolvidas.

Há três fatores a partir dos quais o enunciado pode ser compreendido segundo sua condição extraverbal (Volochinov, 1976): o horizonte espacial compartilhado, o conhecimento e a compreensão comum da situação e a avaliação comum da situação. O horizonte espacial compartilhado entre os interlocutores diz respeito à composição do universo interativo, que pode incluir desde o espaço físico em que se encontram até o contexto sociocultural em que o discurso é produzido. A compreensão comum da situação corresponde à intersubjetividade e envolve o repertório sociocultural que os interlocutores compartilham. Isto se manifesta no discurso na forma de um conhecimento comum que favorece que os interlocutores compreendam os acontecimentos. Já a avaliação comum da situação envolve tudo aquilo que permite analisar criticamente os enunciados e emitir um ponto de vista. Esses três aspectos são fundamentais no processo comunicativo e permitem reconhecer a palavra (enquanto signo ideológico) e o contexto extraverbal como sendo intimamente relacionados. Esse é um aspecto importante quando se nega a análise da palavra isolada. As palavras e os enunciados onde estas se apresentam são apenas a ponta de um iceberg. Seus significados não se encerram naquilo que é materializado na fala ou na escrita. É preciso considerar também aquilo que não foi dito ou escrito, o não verbal. 
A mediação semiótica proveniente de cursos, intervenções do professor, notas escritas, roteiros e outras formas de textos, entendidos aqui como qualquer forma de discurso, oral ou escrito (Lemke, 1990), aprimora o trabalho colaborativo em situações didáticas (Sawyer, \& Berson, 2004). As interações discursivas são populadas por interanimações entre as vozes dos estudantes, acrescendo-se aquelas veiculadas pelo professor no seu discurso verbal e pelos demais recursos semióticos utilizados (Wertsch, 1993), provendo intensa mediação semiótica. Isso enriquece as interações discursivas que, no caso da nossa pesquisa, surgem quando os estudantes tentam compreender os fenômenos físicos envolvidos na simulação com o IVMZ. Assim, é possível afirmar que todo discurso interage com outros discursos sem que com isso se esteja negando uma posição autoral, entendida como uma participação ativa e crítica daquele que produz o enunciado - ao contrário, quem produz o enunciado sempre coloca a sua voz neste, interanimando-a com outras. Nesse sentido, da interanimação, é sempre possível rastrear relações de um discurso com outros discursos, independente de quão original, autônomo ou mesmo autoritário pareça o discurso produzido (Kozulin, 2008). Além disso, é possível perceber que a interpretação de qualquer discurso também tem relações com outros discursos. Esse importante aspecto da interação discursiva é comumente referido como intertextualidade, aspecto importante da dialogicidade e processo pelo qual, segundo Lemke (1992), "todo texto, o discurso de cada ocasião, constrói seu significado social diante do cenário constituído por outros textos e discursos de outras ocasiões" (p. 257). Assim, as relações intertextuais típicas da mediação semiótica acarretam um grande suporte na construção de espaços intersubjetivos - como afirma Kozulin (2008), “a intersubjetividade frequentemente se realiza na intertextualidade” (p. 159).

\section{Simulação do emaranhamento quântico no IVMZ: uma breve caracterização}

A FQ sempre se apresentou como um campo de pesquisa frutífero e repleto de surpresas para aqueles que se dedicaram ao seu estudo. Apesar de, nos anos 60, se imaginar que o único e maior mistério da FQ residia na dualidade onda-partícula (Feynman, Leighton, \& Sands, 1963), ao final dessa mesma década o emaranhamento quântico ganhou espaço entre pesquisadores. Os sistemas emaranhados fazem parte da agenda atual de pesquisa em fundamentos da teoria quântica, especialmente no que diz respeito ao campo da informação quântica. São vários os estudos voltados às aplicações da FQ a sistemas de informação, seja para aumentar a capacidade de processamento de dados com a manipulação de qubits ${ }^{2}$ (computador quântico) (Taddei, Escher, Davidovich, \& de Matos Filho, 2013; Walther et al., 2005;) ou para transferi-los com maior segurança com

2 O qubit consiste na unidade básica de armazenamento de informação em sistemas quânticos. Tanto o bit convencional quanto o qubit seguem a base binária (valores zero e um), entretanto, o qubit permite armazenar informações numa combinação maior de possibilidades. Para o leitor mais familiarizado com a área, cabe destacar que o computador quântico utiliza o princípio da superposição e a interferência como conhecimentos básicos para seu desenvolvimento. 
a utilização da criptografia quântica (Jennewein, Simon, Weihs, Weinfurter, \& Zeilinger, 2000; Loepp, \& Wootters, 2006; Rigolin, \& Rieznik, 2005). Esta tecnologia requer o uso de propriedades dos sistemas emaranhados ${ }^{3}$.

A busca pela compreensão desta estranha correlação entre sistemas quânticos teve início com intensos debates entre Einstein e Bohr, exibindo forte desacordo entre suas interpretações. A continuidade desses debates ocorreu a partir daqueles considerados como dissidentes quânticos, que se dedicavam à pesquisa em fundamentos de Mecânica Quântica (Freire Jr., 2015).

Para Einstein e dois de seus colegas no Instituto para Estudos Avançados, em Princeton (Boris Podolsky e Nathan Rosen), a Mecânica Quântica deveria ser uma teoria física local. Para entender o que significa uma teoria local, vamos tomar como exemplo a Física Clássica (Física Newtoniana que normalmente é estudada durante o Ensino Médio). Nos sistemas clássicos, o efeito da interação entre seus constituintes se propaga com uma velocidade finita. Isso quer dizer que há um intervalo de tempo para que algum efeito se manifeste a partir da alteração nas condições que o produz. É o que ocorre nos sistemas onde a informação se propaga com a velocidade do som, ou da luz, por exemplo. Isso caracteriza a Física Clássica como uma teoria local. Sistemas físicos em que esse intervalo de tempo parece não existir, o que induziria a pensar em formas de comunicação mais rápidas do que a velocidade da luz, manifestam efeitos não locais. Nos sistemas emaranhados, por exemplo em átomos em que uma dada propriedade esteja correlacionada (como se fossem átomos "gêmeos"), o ato de medir e conhecer os valores associados a essa propriedade em um deles permite conhecer, de modo instantâneo, os valores correspondentes a essa mesma propriedade no outro. Isso acontece independente da distância entre ambos. Essa é a essência do fenômeno chamado emaranhamento quântico. Para Einstein, sistemas desse tipo pareciam exibir uma espécie de ação fantasmagórica à distância.

Compreender aspectos contraintuitivos da Mecânica Quântica, como o emaranhamento quântico, não é trivial. Alguns trabalhos, embora nem todos tenham sido produzidos com esse fim, apresentam situações que podem auxiliar na compreensão de aspectos essenciais desse fenômeno de forma mais fenomenológica e em diferentes níveis de aprofundamento. Propostas de abordagens conceituais do fenômeno, normalmente usando analogias, podem ser encontradas na literatura (Bell, 1981; Jacobs, \& Wiseman, 2005; Mermin, 1981; Oliveira, Souza, Sarthour, Reis, \& Soares-Pinto, 2008; Zeilinger, 2005).

A proposta aqui apresentada segue um caminho distinto, pela via da simulação do fenômeno mediada por software. Para isso foi desenvolvida uma remodelagem do IVMZ. Ele possibilita ao aluno e ao professor simular fenômenos que somente poderiam

3 No domínio da FQ, a expressão sistemas emaranhados se refere a sistemas onde seus constituintes apresentam propriedades correlacionadas, como se fossem objetos quânticos "gêmeos". Nesses sistemas, não faz sentido se referir às propriedades de seus constituintes individualmente, ou seja, a única forma de descrever esse sistema é considerando as propriedades dos objetos quânticos enquanto um par, independente da separação espacial entre ambos. 
ser reproduzidos em laboratórios de óptica quântica, com uso de equipamentos caros e sofisticados. Entre as diversas possibilidades incorporadas ao IVMZ na sua remodelagem está a simulação do fenômeno do emaranhamento quântico.

O nosso objetivo é investigar a compreensão dos estudantes e as estratégias utilizadas nesse processo no que diz respeito aos aspectos contraintuitivos do fenômeno, mais do que entender detalhes teóricos mais avançados sobre o fenômeno, para os quais seria indispensável o uso do formalismo matemático. Para o leitor interessado, incluímos como apêndice uma explicação mais detalhada do emaranhamento quântico.

A simulação computacional desse fenômeno consiste no processo de criação de um par de fótons em um estado emaranhado de polarização que interage com dois polaroides, posicionados nos braços A e B do interferômetro (ver Figuras 1 e 2).

A fonte emite um fóton de cada vez, com polarização a 45 graus, e este é convertido em um par de fótons emaranhados em estados de polarização.

Uma vez formado o par emaranhado, todo tratamento, seja no âmbito do formalismo matemático ou da fenomenologia, deve ser realizado sobre o par de fótons interagindo com o par de polaroides, de modo que não faz mais sentido qualquer análise sobre fótons individuais. Após os polaroides há dois detectores, $\mathrm{D}_{\mathrm{A}}$ e $\mathrm{D}_{\mathrm{B}}$, que detectam e absorvem os fótons, de modo que não há interação com os demais dispositivos. Os índices $\mathrm{A}$ e $\mathrm{B}$ fazem referência aos braços do interferômetro e, neste caso, há um fóton do par associado a cada braço. A compreensão do fenômeno requer que se interprete as contagens de fótons nos detectores A e B, mas, para isso, é preciso antes reconhecer as características do par produzido. O par de fótons é produzido de modo que ambos os fótons tenham sempre a mesma polarização (vertical ou horizontal) e cada uma dessas direções de polarização tem probabilidade $1 / 2$ de ocorrer.

Quando os fótons interagem com um polaroide, estes podem ser absorvidos ou transmitidos, dependendo da orientação dos eixos de absorção e transmissão. Esses eixos são sempre perpendiculares entre si. Filtros polaroides ideais transmitem totalmente a componente da luz polarizada na direção paralela ao seu eixo de transmissão, absorvendo totalmente a componente perpendicular a esse eixo (ou paralela ao eixo de absorção, como mostrado na Figura 3). Ao leitor menos familiarizado com esses aspectos, é importante identificar nessa figura a existência dos eixos de absorção e de transmissão e também observar que estes são perpendiculares entre si. A orientação dos eixos de transmissão e absorção dos polaroides é representada em termos de formalismo matemático pela letra grega $\xi$. Para as considerações subsequentes, considere que os polaroides são ideais. 
Dificuldades e Estratégias para Compreensão do Conceito de Emaranhamento Quântico...

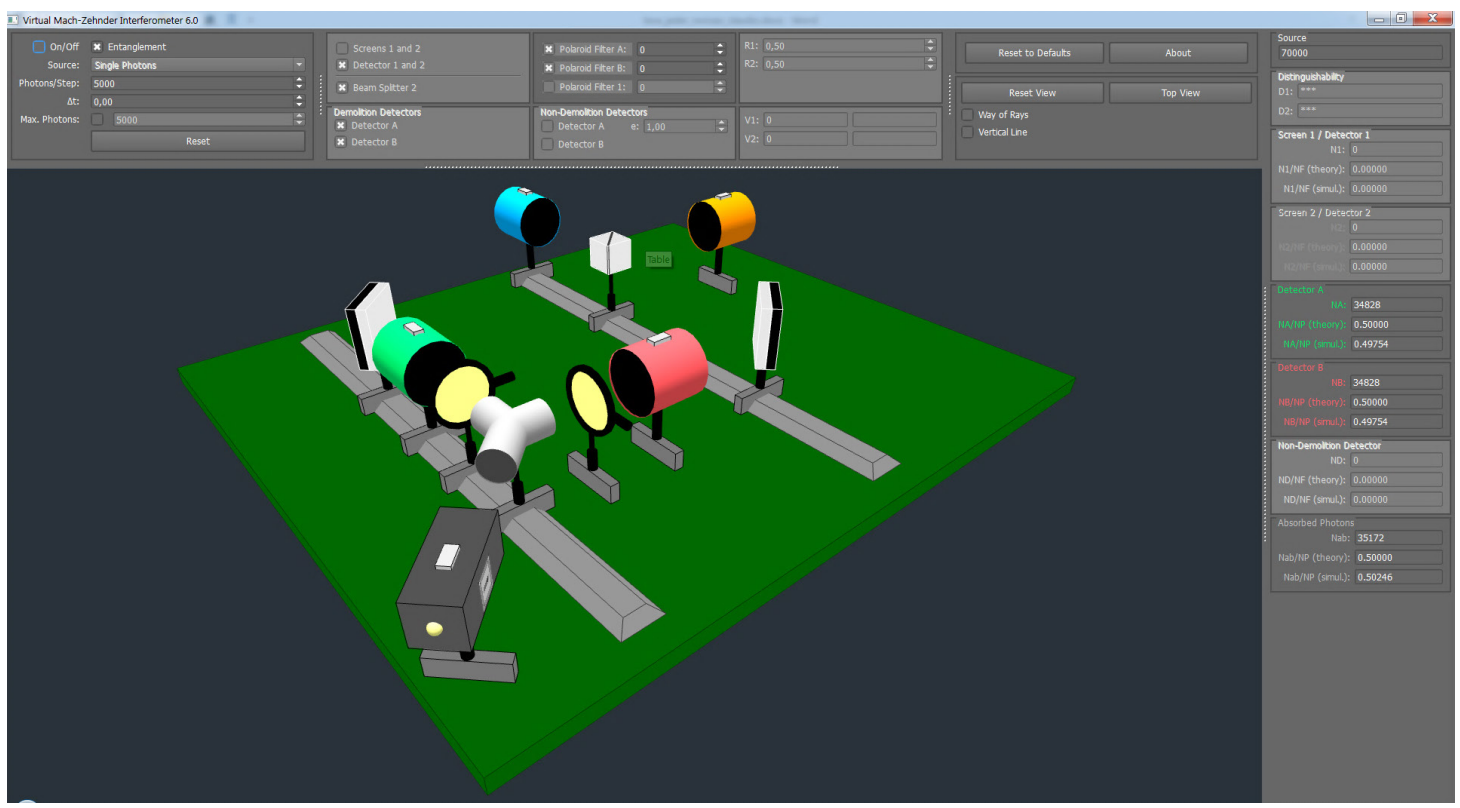

Figura 1. Captura de tela do IVMZ configurado para a simulação do emaranhamento quântico

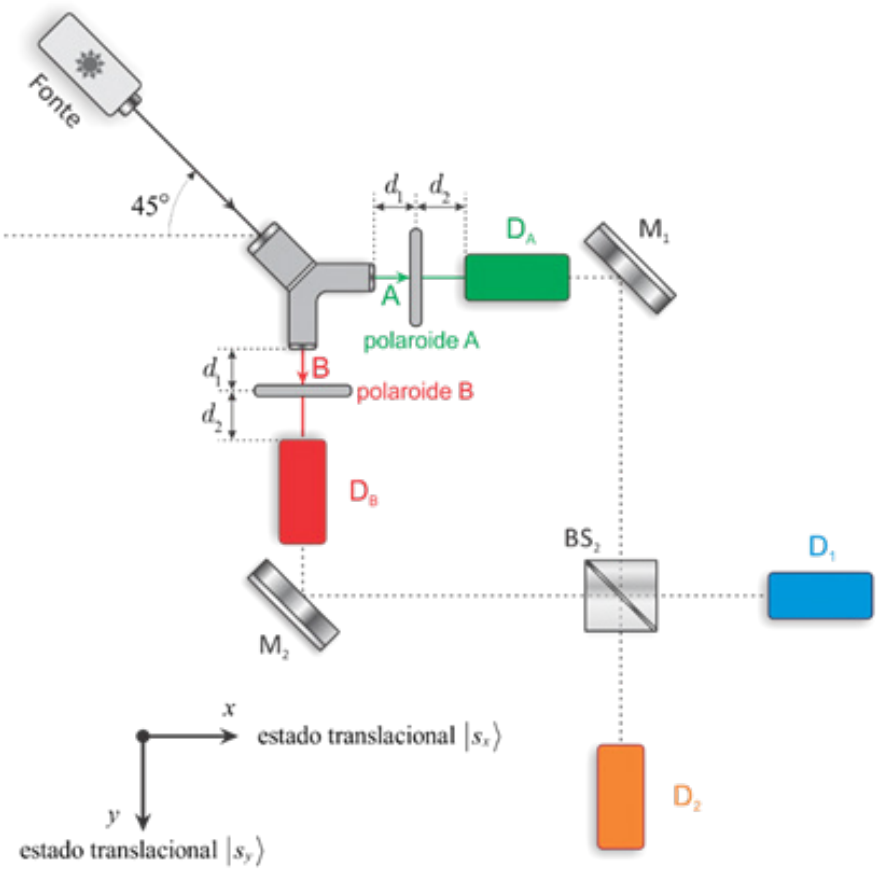

Figura 2. Diagrama simplificado do IVMZ para a simulação do emaranhamento quântico 


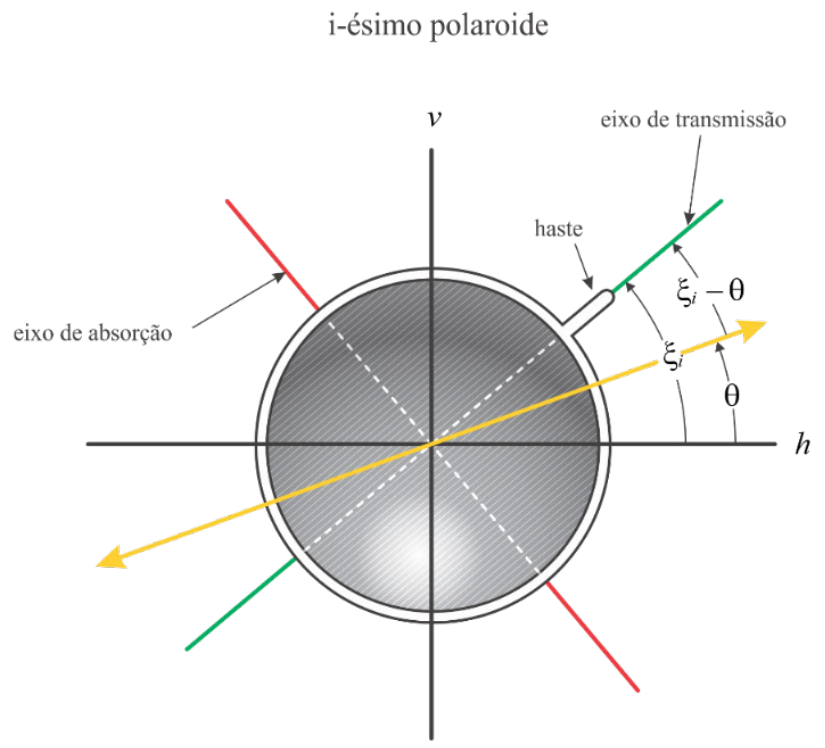

Figura 3. Representação esquemática de um polaroide do interferômetro. Na configuração em que ele simula o emaranhamento há dois polaroides $(\mathrm{i}=\mathrm{A}, \mathrm{B})$, um em cada braço ${ }^{4}$

A probabilidade de os detectores A e B dispararem ao mesmo tempo (cada um acusa um fóton do par - o que se chama coincidência) após a interação dos fótons com os polaroides é igual à probabilidade de ambos serem absorvidos e não haver nenhuma detecção. Essa probabilidade depende da orientação relativa entre os eixos de transmissão dos polaroides, sendo dada por $p_{A B}=(1 / 2) \cos ^{2}\left(\xi_{A}-\xi_{B}\right)$. Para que que os detectores $A$ e B registrem detecção em coincidência, ambos os fótons precisam ser transmitidos nos polaroides posicionados nos braços do interferômetro. Além disso, a probabilidade de apenas um detector (A ou B) disparar, ou seja, de um fóton ser detectado e o outro não, é dada por $\operatorname{sen}^{2}\left(\xi_{\mathrm{A}}-\xi_{\mathrm{B}}\right)$. Na atual versão do software, apenas as coincidências são registradas.

No estudo da Óptica Ondulatória Clássica, aprende-se que um polaroide transmite a luz cuja direção de polarização é paralela ao eixo de transmissão desse dispositivo. No cenário que estamos considerando (o estudo de objetos quânticos emaranhados), é normal que os estudantes esperem um comportamento semelhante (que haja transmissão dos fótons cujo estado de polarização coincide com a direção do eixo de transmissão do polaroide). Entretanto, uma situação bastante contraintuitiva ocorre orientando-se um dos polaroides a 45 graus e outro a 135 graus, por exemplo. Nesse caso, o par sempre será absorvido, não havendo transmissão, mesmo que individualmente os estados de polarização dos fótons não coincidam com a direção ortogonal à direção do eixo de transmissão de algum dos polaroides. Como dissemos, o que se esperaria é que um dos fótons fosse absorvido e o outro transmitido em alguns dos eventos de interação do par com os polaroides. É isso que caracteriza o aspecto não local da teoria quântica,

4 O IVMZ também possibilita a inserção de três polaroides (um em cada braço e mais um na porta de saída 1), para simular o apagador quântico. Este tema será explorado em trabalhos futuros do nosso grupo de pesquisa. 
conforme escrevemos anteriormente. A absorção de um fóton do par emaranhado em um dos polaroides parece determinar a absorção do outro fóton, mesmo que o estado de polarização deste corresponda classicamente a uma direção não ortogonal à direção do eixo de transmissão do polaroide. Este é o aspecto contraintuitivo que mencionamos. Os objetos quânticos em um estado emaranhado devem ser tratados como pares que compartilham determinada propriedade (nesse caso, a direção de polarização), não como objetos individuais.

\section{Procedimentos de coleta e análise de dados}

Esta pesquisa busca entender, sob o enfoque qualitativo, um conjunto de eventos em sua forma natural dentro de um contexto específico. O contexto extraverbal é caracterizado por seis estudantes de uma disciplina de Física Moderna e Contemporânea, ofertada no $6^{\circ}$ semestre do curso de Licenciatura em Física do Instituto Federal de Educação, Ciência e Tecnologia do Rio Grande do Sul - campus Bento Gonçalves. Este é o primeiro contato dos estudantes com a Física do século XX na forma de uma disciplina específica. Os estudantes já tinham conhecimento do trabalho com roteiros exploratórios e com a ferramenta computacional (já haviam utilizado o IVMZ em outros momentos nessa disciplina) e realizaram a atividade em duplas. Essa experiência prévia ocorreu em dois momentos: primeiramente a partir da manipulação do software (simulação da interferência em regime clássico) e, posteriormente, em regime quântico (com e sem polaroides) durante o estudo da complementaridade onda-partícula. Isto acabou criando um espaço intersubjetivo, contribuindo para o estudo de situações mais complexas, nas quais os estados de polarização dos pares de fótons são emaranhados. Esses elementos textuais (roteiros e outros, como as intervenções do professor ao longo das atividades) têm um papel importante na mediação semiótica, crucial para a criação de espaços de intersubjetividade. De modo geral, a disciplina em questão envolve aspectos relacionados à velha FQ e suas origens, princípio de indeterminação, teoria de Schrödinger, postulados da FQ e uma introdução à notação de Dirac. Assim, a discussão do emaranhamento constituiu um tema adicional à ementa da disciplina e foi o último tópico abordado.

O estudo do emaranhamento quântico foi realizado a partir da utilização de outros dispositivos no interferômetro virtual quando comparado com as atividades anteriores de simulação. O primeiro divisor de feixe foi substituído por um dispositivo que simula o papel de dois cristais não lineares para produção de pares de fótons emaranhados em estados de polarização, conforme já foi descrito (ver Figura 1). A atividade contou com um roteiro exploratório fornecido aos estudantes e as interações discursivas foram gravadas em áudio para posterior transcrição ${ }^{5}$ e análise. A atividade de simulação se estendeu por 3 horas-aula. O pesquisador, que também foi o professor da disciplina,

5 Algumas informações que aparecem entre colchetes nos enunciados foram inseridas pelos autores do trabalho. Tratam-se de palavras ou expressões omitidas pelos estudantes no discurso, as quais são subentendidas por eles naquele momento, mas cuja ausência dificultaria a leitura e compreensão dos enunciados. 
destinou 1 hora-aula adicional para esclarecer dúvidas dos estudantes quanto ao fenômeno em si. Isso foi necessário em função de os enunciados produzidos revelarem uma série de dificuldades relacionadas à compreensão desse fenômeno.

A partir de um estudo piloto, realizado no ano anterior com outra turma de estudantes da mesma disciplina, verificou-se a necessidade de corrigir elementos de programação (as contagens nos detectores se referem apenas a detecções simultâneas), além de reformular o roteiro exploratório (Neto, Cavalcanti, \& Ostermann, 2014). Observou-se que a primeira versão desse roteiro apenas tangenciava o tema da não localidade do fenômeno físico estudado, de modo que esse aspecto não chegava a caracterizar um grande problema conceitual aos estudantes. Nessa reformulação do roteiro exploratório, exigia-se que os estudantes fizessem uma previsão sobre o que esperavam em relação aos resultados e, posteriormente, realizassem a simulação comparando os resultados obtidos com o que haviam previsto.

O roteiro exploratório foi estruturado de modo que os estudantes deveriam fazer suas previsões sobre o que esperavam que acontecesse em cada situação explorada no software e, após simularem, apresentar alguma explicação para o que haviam observado. Foram destacadas aqui as principais interações discursivas entre a dupla de estudantes E11 e E12, sendo que E11, do sexo feminino, manipulou o software e E12, do sexo masculino, auxiliou com o roteiro. A opção por esta dupla de estudantes se justifica em função da aderência e relevância dos enunciados ao tema que estava sendo estudado. Além disso, trata-se de estudar com maior profundidade as interações discursivas em diferentes situações e não de comparar diferentes grupos. Assim, optamos por analisar uma quantidade maior de interações discursivas de uma dupla e investigar como suas discussões evoluíram ao longo da atividade. Consideramos que essa estratégia é mais produtiva para essa pesquisa do que apresentar diversos recortes de interações discursivas que poderiam estar desconectadas do todo.

Contexto situacional I - Os estudantes deveriam relacionar o número de fótons emitidos pela fonte com o número de pares detectados, ou absorvidos, além de verificar se ocorriam detecções simultâneas variando a direção do eixo de transmissão dos polaroides em ambos os braços do interferômetro (zero graus, 45 graus e 90 graus), de modo que ambos os polaroides ficassem igualmente orientados. Destacamos três extratos discursivos decorrentes dessas situações. Nesse caso, o estado de polarização do par de fótons após sua interação com os polaroides não é mais emaranhado, pois o estado de polarização do par transmitido é definido pela orientação dos polaroides (vertical, se $\xi_{A}=\xi_{B}=90$ graus, horizontal se $\xi_{A}=\xi_{B}=0$ graus e 45 graus se $\xi_{A}=\xi_{B}=45$ graus). Em qualquer desses casos haverá uma probabilidade de cinquenta por certo de detecção do par nos detectores. A Figura 4 apresenta os enunciados produzidos durante a simulação com os eixos de transmissão de ambos os polaroides orientados a zero graus. 
\begin{tabular}{|l|}
\hline Discutindo a previsão \\
\hline 1. E12: Tem várias possibilidades aí. \\
2. E11: Pois é, será que ainda vale dizer que a \\
polarização é horizontal?
\end{tabular}

3. E12: Não sei, mudou bastante coisa agora. Vamos fazer umas suposições e depois a gente confere.

4. E11: Sim. Se os dois tiverem na horizontal [estado de polarização dos fótons] vão passar sempre e se tiverem na vertical não passam nunca.

5. E12: Beleza, mas pode tá um na horizontal e outro na vertical.

6. E11: Será que vai ter isso?

7. E12: Sei lá, tudo é possível. Nesse caso só vai passar num lado, onde vai os que tão na horizontal. [Estudante faz as anotações no roteiro].

8. E11: Tem o que ali?

9. E12: Se vai ter deteç̧ão simultânea?

10. E11: Isso não. Lembra lá da outra atividade?

11. E12: Ahan. Não pode, não divide.

12. [Silêncio].

Figura 4. Extrato referente à simulação com os eixos de transmissão dos polaroides orientados a zero graus

Inicialmente, E11 e E12 expressam verbalmente a impossibilidade de inferir com certeza o estado de polarização do par de fótons (enunciados 1 e 2). Essa afirmação está correta, pois o estado de polarização do par de fótons produzidos não é definido ${ }^{6}$. Assim, os estudantes interanimam as vozes que veiculam e propõem três alternativas ao fazerem suas previsões (enunciados 4 e 5). Em duas dessas possibilidades (enunciado 4) os fótons são tratados como par em que ambos estão com estado de polarização horizontal ou ambos com polarização vertical. No terceiro caso (enunciado 5) o par de fótons é tratado como cada objeto do par se encontrando em estados de polarização ortogonais (um fóton com estado de polarização horizontal e o outro com polarização vertical), o que implica outra possibilidade de resposta (enunciado 7). Estas hipóteses são mediadas por vozes que surgem a partir da simulação realizada anteriormente com polaroides e um feixe de luz laser (fonte operando em regime clássico). As possibilidades de absorção e transmissão apontadas pela dupla retomam enunciados de um contexto

6 Pode-se mostrar que o estado do par é representado por uma superposição de dois estados, um em que os dois fótons se encontram no estado horizontal e outro em que os fótons estão no estado vertical. Em uma medição, cada um desses estados têm probabilidade $1 / 2$ de ocorrer.
Discutindo o resultado as contas. são pares. Cada um dá dois.

17. E11: É. Óh, agora é simultâneo, por causa que é um par.

18. E12: Ah é, agora pode.

19. [Silêncio].

20. E11: Já sei, óh. A polarização em cada lado

21. E12: Bo::a.

22. E11: Pega os da direita, óh [braço B]. passa e na outra metade tá vertical e não passa.

24. ... No outro lado a mesma coisa.
13. E11: Como assim? A metade!

14. E12: Haha, tava bom demais pra ser verdade.

6. E12: É mesmo, tem mais fótons. ... Ah não, 
situacional anterior, configurando uma intertextualidade bakhtiniana e sinalizando que o espaço de intersubjetividade foi estabelecido. Entretanto, são contextos experimentais distintos. Isso, apesar de dificultar o entendimento da situação proposta (fótons emaranhados), foi intencional no sentido de fazer com que os estudantes percebessem anomalias entre suas previsões e os resultados observados na simulação. $\mathrm{O}$ mesmo acontece quando E11 (enunciado 10) lembra E12 da impossibilidade de divisão do fóton, tema já debatido anteriormente, na atividade com a fonte emitindo fótons únicos. Há falas mediadas por roteiros e situações externas à situação proposta, no sentido de tentar compreender a situação nova que foi apresentada por meio da interanimação das vozes veiculadas por E11 e E12 com aquelas vozes (perspectivas). As expressões de surpresa de E11 (enunciado 13) e E12 (enunciado 14) são fruto do resultado completamente inesperado exibido nos detectores. O que inicialmente parece ser um problema de cálculo (enunciados 15-16) conduz os estudantes a uma quarta possibilidade para os estados de polarização (enunciado 20) que, momentaneamente, parece atender as suas necessidades (enunciados 22-24). Em todos os momentos é explícita a mediação do software, roteiros anteriores e as discussões ocorridas no curso como um todo.

Duas expressões utilizadas pelos estudantes como recursos semióticos pictóricos acabam se configurando como contrapalavras importantes por estarem associadas a uma possível representação dos fótons para se referir ao estado de polarização. Tanto E12 (enunciado 7) quanto E11 (enunciado 23) se referem ao fato de o fóton estar na horizontal ou estar na vertical. É flagrante a presença de uma voz discursiva pertencente à Física Clássica, estabelecendo uma forte analogia com a direção de oscilação do vetor campo elétrico. Se por um lado isso explica classicamente a polarização, a forma como essas contrapalavras são empregadas parece se referir ao fóton, como algo que está, fisicamente, numa dada direção. As Figuras 5 e 6 apresentam, respectivamente, os enunciados produzidos durante a simulação com os eixos de transmissão de ambos os polaroides orientados a 45 e 90 graus.

Ao se referirem ao estado de polarização dos fótons, os estudantes, implicitamente, acabam tomando como sinônimos a direção de polarização (enunciados 26 e 41) e uma possível representação de algo que se encontra, de fato, naquela direção (retornar aos enunciados 7 e 23). Segundo a perspectiva da FQ, a direção de polarização do fóton está relacionada ao seu spin.

O modelo explicativo adotado pelos estudantes foi colaborativamente construído no primeiro extrato discursivo (ver Figura 4) como um estado de 'polarização variável', em que aproximadamente a metade dos eventos de interação com os polaroides se dá com o par emaranhado em polarização vertical e na outra metade com polarização horizontal. Tal modelo mostra-se útil para fazer as previsões (enunciados 25-26 e 41-42) e para explicar (enunciados 35 e 44) os resultados obtidos, necessitando de um ajuste (enunciado 26) para dar conta de configurações diferentes de polaroides. Esse modelo, embora venha a se mostrar inconsistente para outras situações, conforme será visto mais adiante, é um resultado importante da atividade com o software e o 
roteiro atuando como ferramentas mediadoras. Mesmo que seja um modelo explicativo incipiente, nota-se como a mediação foi importante na sua construção. Ambos os estudantes, colaborativamente, esboçam a ideia (correta) de que os fótons do par estão no mesmo estado de polarização, vertical ou horizontal. Parece mais claro que ambos são corresponsáveis pela explicação, fruto de relações dialógicas com outros textos (roteiros, falas do professor no curso e outros). Quando o roteiro fornece algumas orientações e deixa os estudantes livres para interagir com o software (enunciados 39-40), criam-se situações que podem levar a interpretações divergentes. No caso de E11 e E12, a ideia de atribuir um estado de polarização variável foi bastante interessante e, até certo ponto, não está muito distante daquilo que será utilizado para explicação do emaranhamento quântico.

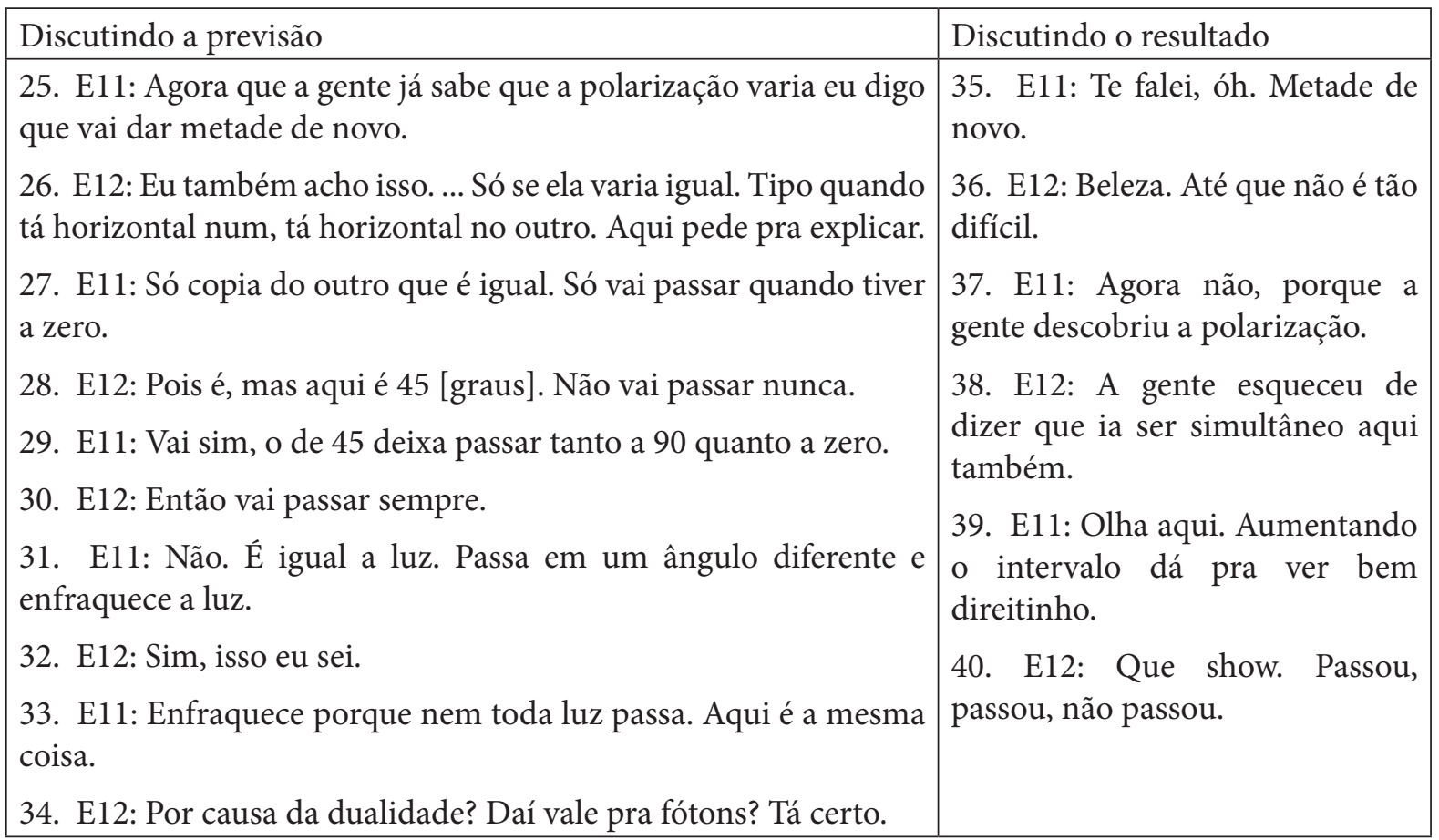

Figura 5. Extrato referente à simulação com os eixos de transmissão dos polaroides orientados a 45 graus

\begin{tabular}{|l|l|}
\hline Discutindo a previsão & Discutindo o resultado \\
\hline $\begin{array}{l}\text { 41. E12: Agora vai passar aqueles que estão com a polarização } \\
\text { horizontal. }\end{array}$ & $\begin{array}{l}\text { 44.. E12: O que foi mesmo que eu te } \\
\text { disse? Metade de novo. }\end{array}$ \\
$\begin{array}{l}\text { 42. E11: A metade dos fótons. } \\
\text { 43. E12: Isso, a outra metade fica no polaroide [é absorvida]. }\end{array}$ & \\
\hline
\end{tabular}

Figura 6. Extrato referente à simulação com os eixos de transmissão dos polaroides orientados a 90 graus

Contexto situacional II - Os estudantes deveriam analisar a probabilidade de ocorrência de detecções simultâneas no caso em que os eixos de transmissão dos polaroides estão perpendiculares, ou cruzados, entre si, de modo que um polaroide estivesse orientado a 45 graus e o outro a 135 graus. Em seguida, eram solicitados a contrastar essa previsão com o que haviam discutido anteriormente (quando a fonte 
emite fótons únicos e estes interagem com um polaroide orientado a 45 graus). Nesse caso, nunca são acusadas coincidências, ou seja, nunca o par emaranhado é transmitido ou absorvido ${ }^{7}$. Esse resultado é bastante contraintuitivo, uma vez que os estudantes esperam que em algumas vezes os fótons possam ser transmitidos (ou absorvidos) conjuntamente. A problemática reside no fato de os estudantes reconhecerem os fótons como sendo objetos quânticos individuais ao invés de pares correlacionados. A Figura 7 ilustra a previsão realizada pela dupla.

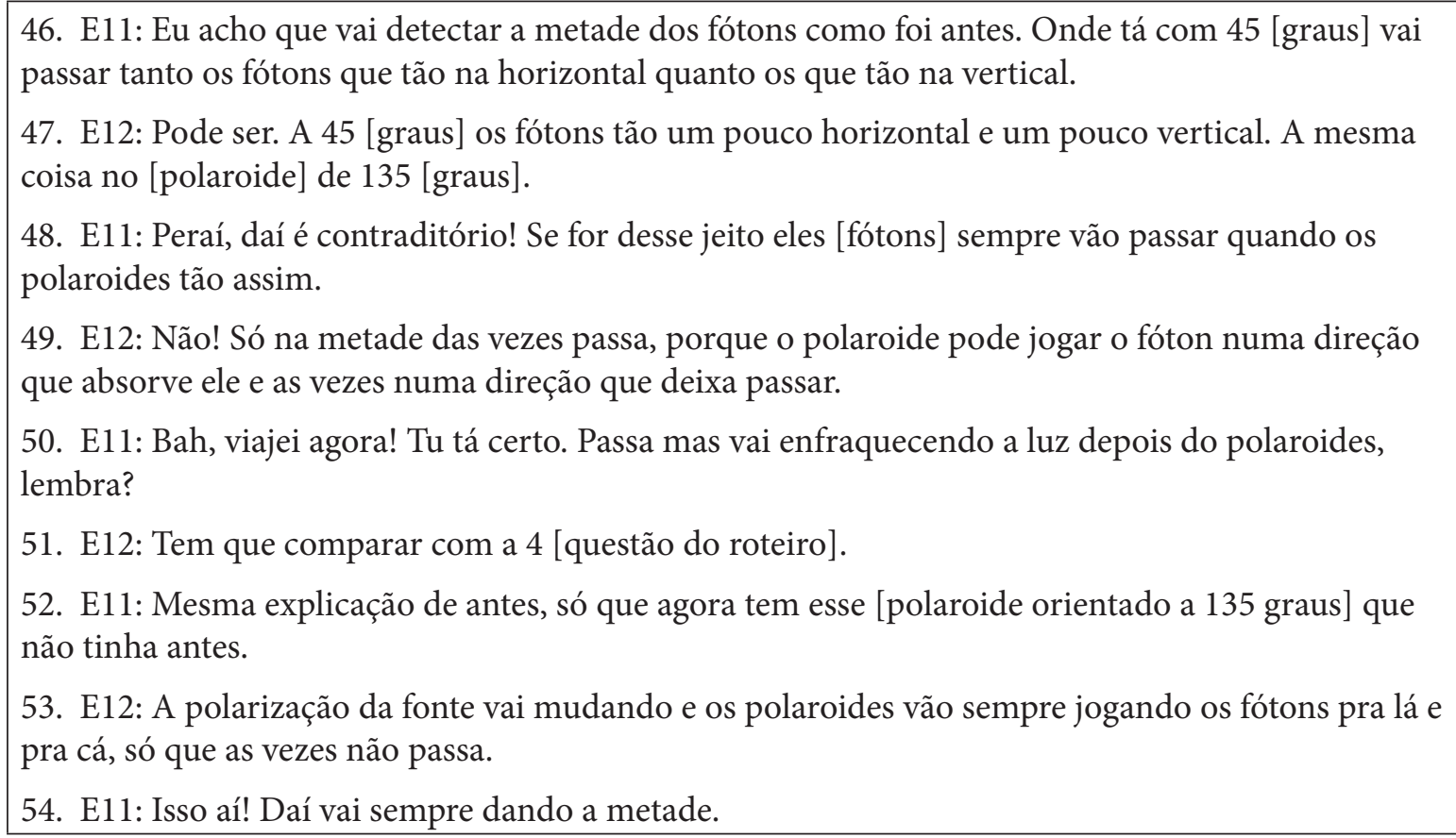

Figura 7. Previsão referente à simulação com os eixos de transmissão dos polaroides cruzados (um orientado a 45 graus e o outro a 135 graus)

A estratégia adotada pela dupla (fonte com polarização variável) parece ser realmente consistente para ambos os estudantes. Tal estratégia permitiu que os estudantes explicassem tanto o contexto situacional em que os polaroides estão orientados na mesma direção quando o contexto no qual estas direções estão cruzadas (um polaroide a 45 e o outro a 135 graus). Até este momento, ambos os estudantes popularam o discurso com uma voz que privilegiava a existência de uma correlação clássica entre os estados de polarização dos fótons - em oposição a uma voz, não veiculada explicitamente, que assumisse que a correlação fosse quântica (par emaranhado). Da análise realizada, até o momento, sobre os enunciados nessas interações discursivas envolvendo polaroides e a geração de pares de fótons se pode dizer que E11 e E12 compartilham uma definição de situação com boa sintonia mútua (enunciados 46-47 e 52-54), embora inicialmente E11 pareça ter discordado do colega (enunciados 48-49). A intersubjetividade construída, nesse caso, se deu em um nível tal que ambos os estudantes adotaram praticamente

7 Para o leitor que se interessar em realizar o cálculo, a probabilidade de transmissão do par de fótons é dada por $p_{A B}=(1 / 2) \cos ^{2}\left(\xi_{A}-\xi_{B}\right)=0$. 
as mesmas representações para os objetos e eventos, o que lhes possibilitou prosseguir na atividade com fluência mesmo com as esperadas dificuldades conceituais acerca do fenômeno. Por outro lado, a definição de situação compartilhada pelos estudantes não parece ajudar no sentido de resolver o problema ou de criar condições para a abertura da ZDP entre ambos. Isso vem à tona quando os estudantes observam as contagens nos detectores na situação em que é gerado um par de fótons e o eixo de transmissão de um polaroide está orientado a 45 graus e o do outro a 135 graus (ver contexto situacional IV). Os estudantes também estão de acordo quanto à forma de reconhecer o fóton, apropriando-se de uma voz discursiva da Física Clássica que em nada serve para explicar as contagens e que ainda fomenta uma noção equivocada sobre o fenômeno. $\mathrm{O}$ estudante E12 (enunciado 47) se refere explicitamente ao fóton estar na vertical ou na horizontal, numa representação que é plenamente acolhida pela colega (enunciado 50). É interessante observar que o estudante E12 (enunciados 49 e 53) utiliza o termo jogar para se referir à ação dos polaroides sobre os fótons. Embora esse termo seja utilizado para se referir a uma possível orientação do objeto quântico (representando uma noção clássica sobre polarização), o mesmo parece suscitar a noção de que o que ocorre é uma projeção. Nesse caso, jogar o fóton pode ser interpretado como sendo uma contrapalavra para, possivelmente, se referir à projeção do estado de polarização do fóton numa dada direção.

Contexto situacional III - Apresentou-se aos estudantes uma situação que buscava colocá-los em contradição quanto ao recurso explicativo adotado anteriormente. A ideia era criar um espaço intersubjetivo no sentido de levar os estudantes a perceber a anomalia - a situação completamente diferente que resulta da interação de um par fótons com polaroides quando os objetos do par são independentes e quando estão emaranhados. Para isso, foi elaborado o experimento mental descrito na Figura 8 para servir como uma representação externa (Sawyer, \& Berson, 2004) que provê parte da mediação semiótica para estabelecer esse espaço intersubjetivo.

A dupla precisava analisar essa montagem experimental, que consiste em um interferômetro de Mach-Zehnder com duas fontes individuais, cada uma emitindo um fóton por vez. Supõe-se que os fótons são emitidos simultaneamente e que o par tem sempre a mesma polarização (quando uma fonte emite um fóton com polarização horizontal, a outra também emite outro com polarização horizontal, o mesmo acontecendo com a emissão de um par com polarização vertical). Além disso, aleatoriamente, o estado de polarização dos fótons emitidos varia de forma que em aproximadamente metade das vezes os fótons são produzidos com polarização horizontal e nas vezes restantes com polarização vertical ${ }^{8}$. É importante destacar que, nesse contexto experimental específico, os fótons não são emaranhados.

8 Essa situação não foi implementada no IVMZ, mas pode se mostrar que o estado de polarização dos fótons não é emaranhado. O estado do par nesse caso corresponde a uma mistura estatística dos dois estados de polarização possíveis, ambos os fótons na polarização vertical ou horizontal, cada um desses estados com probabilidade 1/2 de ocorrer. Isso acarreta em uma correlação clássica entre os fótons do par. 


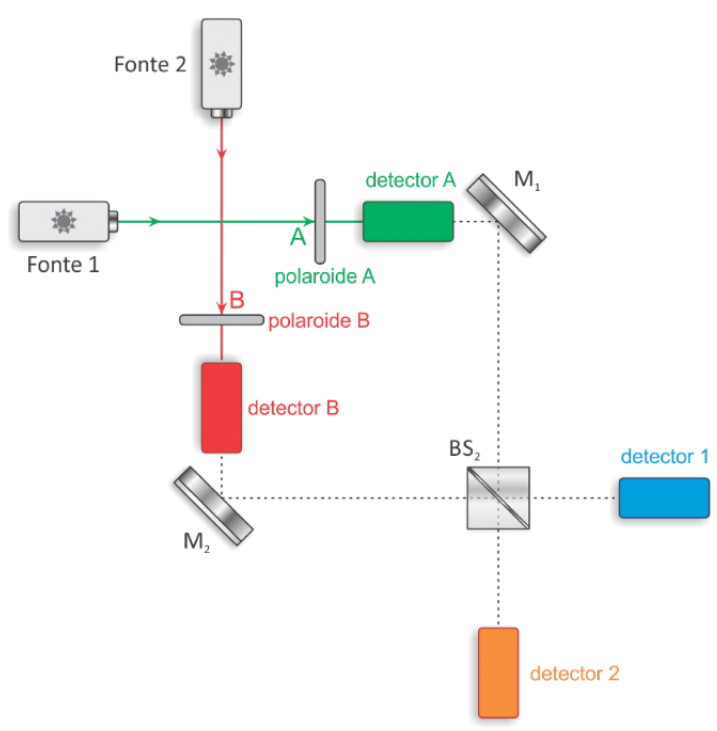

Figura 8. Experimento mental proposto

Nesse contexto situacional, os estudantes são questionados em relação à contagem de fótons detectados simultaneamente se os polaroides nos braços do interferômetro estiverem orientados nas seguintes configurações: ambos a zero graus, ambos a 45 graus, ambos a 90 graus, um a zero graus e outro a 90 graus e um a 45 graus e o outro a 135 graus. A análise do dispositivo que representa o experimento mental permite concluir que, para o caso em que um dos polaroides está orientado a zero graus e o outro a 90 graus, não há detecções simultâneas nos detectores A e B. Isso ocorre porque ambas as fontes emitem fótons com o mesmo estado de polarização e, assim, um dos fótons sempre será absorvido por um dos polaroides. Alterando-se as configurações de polaroides, de modo que estes se encontrem ambos a zero ou ambos a 90 graus, a contagem de fótons nos detectores revelaria que, aproximadamente, a metade do total de fótons emitidos por cada fonte seria detectada simultaneamente após os polaroides. Esses três casos não são suficientes para diferenciar claramente entre o tratamento dado a pares de fótons emaranhados de interpretações clássicas baseadas em objetos quânticos independentes, uma vez que os resultados obtidos são iguais para os dois sistemas. Também podem ocorrer detecções simultâneas se ambos os polaroides estão orientados a 45 graus ou um polaroide a 45 graus e o outro a 135 graus, entretanto, essa probabilidade 9 se reduz para 1/4. A Figura 9 apresenta o extrato relativo às previsões realizadas pelos estudantes para o contexto proposto no experimento mental da Figura 8.

9 Nesses casos, a probabilidade de deteç̧ão simultânea, ou seja, da transmissão do par, é dada por $p_{\mathrm{AB}}=(1 / 2)$ $\cos ^{2} \xi_{A} \cos ^{2} \xi_{B}+(1 / 2) \operatorname{sen}^{2} \xi_{A} \operatorname{sen}^{2} \xi_{B}$. O primeiro termo é a probabilidade de transmissão conjunta quando o par é criado no estado de polarização horizontal, dado pelo produto das seguintes probabilidades: do par ser criado nesse estado de polarização (1/2), do fóton 1 ser transmitido pelo polaroide $\mathrm{A}\left(\cos ^{2} \xi_{A}\right)$ e, do fóton 2 ser transmitido pelo polaroide $B\left(\cos ^{2} \xi_{B}\right)$. Raciocínio análogo permite concluir que o segundo termo é a probabilidade de transmissão conjunta do par quando ele é criado no estado de polarização vertical. Note que essa probabilidade é bastante distinta da probabilidade de transmissão conjunta $p_{\mathrm{AB}}=(1 / 2) \cos ^{2}\left(\xi_{A}-\xi_{B}\right)$, no caso em que o par é criado em um estado emaranhado. 
55. E12: Pra mim vai continuar sendo sempre a mesma coisa, a metade.

56. E11: Tá perguntando sobre as detecções simultâneas.

57. E12: Se uma fonte emite um fóton na horizontal a outra também e daí passa num lado, quando emitir na vertical vai ser vertical nas duas e daí passa do outro lado.

58. E11: Tá, mas isso daí pra quando um [polaroide] tá a zero [graus] e o outro a 90. Vai detectar a metade sim, mas nunca vai ser ao mesmo tempo.

59. E12: Nos outros também. Óh: se os dois [polaroides] tão a zero [graus] vai passar fótons toda vez que eles são na horizontal e isso ocorre a metade das vezes, porque na outra metade a fonte emite na vertical.

60. E11: Tudo bem. E vão ser simultâneas, porque os dois polaroides tão na mesma condição.

61. E12: Isso daí. E quando os dois [polaroides] tão a 90 [graus] isso acontece com os [fótons] que tão na vertical.

62. E11: Perfeito.

63. E12: Então, qual é o problema?

64. E11: Com 45 e 135 [graus] eu tô achando que vai dar .

65. E12: Não! É a mesma explicação de novo. O [polaroide] de 45 [graus] joga os fótons pra horizontal e pra vertical e vai fazer isso na metade das vezes. A mesma coisa no [polaroide] de 135.

66. E11: Sim, mas pra detectar ao mesmo tempo tem que multiplicar as duas probabilidades, daí vai dar. A gente esqueceu disso antes.

67. E12: Sim, sim, é isso. É só corrigir aquele de antes. É mesmo. Eu tava pensando só nas detecções. Não me liguei que tava perguntando se era junto [detecções simultâneas].

Figura 9. Extrato relativo ao experimento mental

Os estudantes respondem ao que foi solicitado com certa tranquilidade, visto que nenhuma 'anomalia' parece ter sido percebida em relação ao contexto explorado anteriormente. E11 chegou a um valor para a probabilidade de detecções simultâneas diferente (enunciado 64) daquele que a dupla havia proposto anteriormente para um polaroide orientado a 45 graus e o outro a 135 graus no contexto situacional II (enunciados 49 e 50). Entretanto, isto foi encarado como sendo apenas um descuido em relação ao que estava sendo solicitado no roteiro exploratório (enunciados 66 e 67). Nesse sentido, pode-se dizer que E11 e E12 compartilham a mesma definição de situação, dada a forma como representam o estado de polarização do fóton e a natureza da explicação fornecida para os resultados. A análise das diferentes combinações de polaroides realizadas neste contexto situacional permite evidenciar que o modelo explicativo utilizado pelos estudantes não foi alterado (enunciado 57 e início do enunciado 58). Estes reconhecem os fótons como sendo objetos quânticos independentes, tanto no caso do experimento mental com fontes individuais quanto para fótons emaranhados. As explicações fornecidas pelos estudantes mantém a mesma estrutura argumentativa apresentada anteriormente no contexto situacional II (enunciados 49, 50 e 53).

Contexto situacional IV - Os estudantes puderam observar no IVMZ as contagens nos detectores para a situação que haviam feito uma previsão (contexto situacional II), 
em que um polaroide está orientado a 45 graus e o outro a 135 graus e a fonte emite pares de fótons emaranhados. $\mathrm{O}$ caráter contraintuitivo do fenômeno estudado se manifesta a partir da divergência entre a previsão feita pelos estudantes e o resultado obtido. Isso se torna ainda mais evidente quando os estudantes tentam elaborar outra explicação, mas esta não satisfaz outros resultados que eles haviam explicado anteriormente (ver Figura 10).

\footnotetext{
68. E11: Não pode ser! Não tem detecção!

69. E12: Como assim? Não detecta?

70. E11: Tinha que ser aqui também!

71. E12: Tem coisa errada aí.

72. E11: Bah, agora tá muito estranho! Tinha que detectar alguma coisa.

73. E12: Agora eu tô perdido! Já vi que não entendi nada.
}

74. E11: Olha aqui óh! A gente acertou a probabilidade pra todos os casos, só com 45 e 135 [polaroides cruzados] é que não deu certo.

75. E12: Sem explicação. Como que o fóton horizontal não vai passar em 45 [graus] ou em 135 ?

76. E11: Não é que ele não passe. Ele passa. A questão é que quando passa num não passa no outro. Isso é que eu não entendi. O pior é que eu não vejo como explicar isso sem mudar a explicação das outras [configurações de polaroides].

77. E12: Professor! Isso aqui tá muito estranho.

Figura 10. Proposta de uma explicação para o resultado obtido com o eixo de transmissão de um dos polaroides a 45 graus e do outro a 135 graus

O reconhecimento do aspecto contraintuitivo do fenômeno simulado foi discursivamente manifestado pelos estudantes a partir do comportamento não esperado do par emaranhado na interação com os polaroides (enunciados 68-71), situação apenas aparentemente similar à que é proposta na Figura 8. Nesse instante, claramente a fala remete ao contexto situacional III, ou seja, incorpora as vozes lá veiculadas (fótons cujos estados de polarização não estão emaranhados, mas classicamente correlacionados). Para E12, o resultado parece não fazer nenhum sentido, pois ele põe em dúvida a simulação ou sua execução (enunciado 71) e até mesmo seu próprio conhecimento (enunciado 73). Assim, a inserção proposital do contexto situacional III foi essencial como ponto de partida para a discussão do caráter não local do processo de medição em sistemas emaranhados. Sua compreensão não é trivial e não se esperou que o software e o roteiro pudessem, isoladamente, levar a isso. O objetivo foi muito mais direcionado a fazer os estudantes entenderem o grande problema conceitual que tinham pela frente, com a mediação do IVMZ e roteiros. A partir desse ponto, a intervenção do professor (enunciado 77) foi imprescindível para que os estudantes conseguissem estabelecer uma representação mais clara do fenômeno físico.

Há ainda dois conceitos que precisam ser retomados e que não abordamos de forma pontual nas análises dos enunciados, mas o fazemos agora, após ter uma visão geral de como transcorreu a atividade como um todo. Trata-se do domínio e apropriação de uma ferramenta cultural. A sequência de enunciados mostra que os estudantes 
conseguem manipular o software, reconhecer o funcionamento dos seus dispositivos e, a partir disso, prosseguir na atividade. Consideramos que isso reflete o domínio sobre o software enquanto ferramenta cultural. Por outro lado, tomando a perspectiva dos signos, podemos dizer que a sua compreensão é ainda incipiente. Chama atenção o fato de os estudantes exibirem, de modo hesitante, uma concepção equivocada sobre o fóton como objeto quântico e seu estado de polarização. Em alguns enunciados, já destacados nas análises, há referência ao estado de polarização do fóton, enquanto outros revelam uma tentativa de representação do fóton propriamente. Assim, tomando o software como ferramenta cultural e o significado atribuído aos signos, falamos em termos de domínio parcial.

Não faz sentido argumentarmos em termos de apropriação da ferramenta cultural. A apropriação envolve o que Wertsch (1985) chama de princípio da descontextualização de instrumentos de mediação "e consiste no processo pelo qual o significado dos signos torna-se cada vez menos dependente do contexto espaço-temporal único em que são utilizados" (p. 33). Tomando a simulação no IVMZ, isso implicaria, por exemplo, um estudante ser capaz de compreender o fenômeno do emaranhamento quântico num contexto diferente, como o que pode ser obtido retirando-se os polaroides e os detectores dos braços do interferômetro. Esse novo cenário envolve o estudo do emaranhamento em estados translacionais de pares de fótons - nesse caso, as contagens em um ou outro detector nas portas de saída do interferômetro ocorrem de modo que sempre os dois fótons são detectados juntos, no mesmo dispositivo, se o segundo divisor de feixe tiver coeficientes de reflexão (e transmissão) iguais a 1/2. Isso envolveria outro estudo, que nessa versão do IVMZ ainda não pode ser realizado. A instabilidade da relação que os estudantes mantêm com a ferramenta cultural nesse estudo, ou seja, a forma com que reconhecem o significado dos signos (estado de polarização e fótons emaranhados), por si só, dificultaria sua utilização em um contexto diverso. Isso, entretanto, não inviabiliza a realização da atividade como processo de ensino e ainda permite tornar explícitos significados que os estudantes constroem e que poderiam não ser percebidos em outro formato de atividade, como em uma aula expositiva. O contexto desafiador que foi apresentado aos estudantes fez com que estes tomassem o problema a ser resolvido como um problema seu e não como algo fictício e distante, tal como pode ocorrer em relação aos questionamentos que figuram em listas de exercícios ao final de um capítulo do livro.

O desafio apresentado aos estudantes no roteiro exploratório (elaborar um modelo explicativo para o fenômeno em questão - emaranhamento quântico) buscou criar uma zona de desenvolvimento proximal e, tomando a perspectiva adotada por Wertsch em relação a esse conceito, podemos considerar que esse objetivo foi plenamente alcançado (Wertsch, 1984). Isso possibilitou identificar a forte presença de contrapalavras e vozes discursivas pertencentes à Física Clássica, mesmo ao final de uma disciplina que explora unicamente o universo da FQ. Tem-se aqui um resultado importante que se relaciona com os estudos que investigam mudança discursiva. Além disso, é evidenciado o papel mediador do software no processo de elaboração dos modelos explicativos dos estudantes. 
A ideia de que a luz 'enfraquece' após a interação com um polaroide, apesar de empregar uma linguagem informal, é coerente tanto no contexto da Física Clássica quanto da Quântica. Isso diz respeito ao efeito produzido na luz pela ação de um polaroide. A interpretação, ou representação, de como esse efeito ocorre é que acaba se constituindo como uma dificuldade para os estudantes. A representação da luz na perspectiva da Física Clássica, recorrendo à noção de um campo elétrico que efetivamente oscila numa ou noutra direção é que acaba constituindo um obstáculo para os estudantes em termos de descrever os estados de polarização dos fótons. Esses objetos quânticos tendem a ser considerados pelos estudantes como algo que "transporta" um campo elétrico que fisicamente possui uma dada direção e sentido. Isso, além de evidenciar uma dificuldade em compreender a superposição de estados, parece remeter à atribuição de uma forma para os fótons que 'estão na horizontal ou na vertical' (enunciados 7, 23, 26, 41 e 46).

Considerando o cenário das aulas mais tradicionais, centradas na exposição de conteúdos pelo professor, essas representações poderiam permanecer camufladas no discurso dos estudantes, fomentando um modelo semiclássico para o fenômeno da polarização. Nesse sentido, a mediação pela simulação computacional e pelo roteiro exploratório permite evidenciar tais noções. Em termos práticos, isso reforça a importância de o professor propiciar momentos em que o estudante precise explicar e argumentar. Mais do que isso, é preciso avançar para cenários que explorem as limitações dessas explicações e argumentos e estar atento aos discursos dos estudantes em sala de aula. No cenário da simulação computacional realizada, somente a exposição dos alunos a um contexto desafiador, como o estudo do emaranhamento quântico, foi capaz de evidenciar as sérias limitações dos seus modelos explicativos. A fronteira entre dois universos bastante distintos como o clássico e o quântico requer a reformulação de alguns conceitos e formas de interpretação.

Esses resultados fortalecem ainda mais o papel das análises discursivas enquanto metodologia de pesquisa, uma vez que evidenciam conceitos e relações importantes que poderiam não ser manifestados e transmitirem a falsa impressão de aprendizagem de conceitos científicos.

\section{Conclusões}

A utilização do software enquanto ferramenta cultural possibilitou aos estudantes fazer alterações deliberadas na configuração dos dispositivos e, com isso, determinar as estratégias que seriam adotadas, bem como empreender a negociação de uma definição de situação intersubjetiva. Por outro lado, apenas o fato de compartilharem uma definição de situação não é uma garantia de que as estratégias utilizadas conduzam à aprendizagem dos conceitos em questão, como mostra o contexto situacional I (enunciados 4-7). A noção de não localidade, necessária para a compreensão do emaranhamento quântico, mesmo que não tenha sido plenamente reconhecida pelos estudantes nas interações discursivas aqui apresentadas, proporcionou eventos discursivos interessantes, em que estes tentaram sofisticar seus modelos explicativos de diversas formas a fim de 
conseguirem dar alguma explicação plausível para este complexo fenômeno.

Em se tratando de uma pesquisa realizada sob um enfoque sociocultural, não cabe fazer comparações no sentido de afirmar que um estudante aprendeu mais do que o outro, mas de analisar as estratégias discursivas envolvidas (o processo foi o foco da investigação, não tanto os resultados). É na tentativa de formulação e utilização dos modelos explicativos pelos estudantes que o professor pode identificar aspectos relevantes, proporcionando que as 'rotas dialógicas' conduzam os estudantes no sentido de se apropriarem dos conceitos em estudo. A simulação no IVMZ com os roteiros exploratórios contribui nesse sentido e espera-se que esta ferramenta venha a promover a abordagem de temas mais atuais da FQ na formação de professores de Física, como o emaranhamento quântico, tratado neste trabalho.

A intervenção realizada a partir do IVMZ como ferramenta mediadora nesse contexto sociocultural conseguiu evidenciar as dificuldades dos professores em formação em conciliar suas concepções (com profundas raízes na Física Clássica) com questões de natureza essencialmente quântica. Entender a inseparabilidade de estados quânticos, por exemplo, exige dos estudantes uma mudança discursiva profunda. Isso tem um impacto considerável na formação inicial do professor de Física que, por sua vez, reflete na forma com que futuramente venha a abordar temas da FQ nas suas aulas no Ensino Médio. Nesse sentido, esta pesquisa abre espaço para novos estudos relacionados à mudança discursiva, particularmente, em FQ na formação inicial de professores de Física.

Consideramos que esse estudo e os referenciais teóricos utilizados podem contribuir com a área de Ensino de Ciências no que diz respeito à busca pela compreensão dos processos de apropriação de conceitos. A análise das interações discursivas pautada em conceitos da teoria da mediação de Vygotsky e da filosofia linguística de Bakhtin permitiu evidenciar dificuldades conceituais dos estudantes que poderiam passar despercebidas no contexto de aulas mais tradicionais. Situações mais desafiadoras, como as que foram apresentadas num contexto de simulação computacional, fazem emergir construções conceituais elaboradas pelos estudantes e que podem ter grande influência em seus processos de aprendizagem. Outra contribuição dessa pesquisa, no sentido de sinalizar para a realização de novos estudos, está relacionada à investigação sobre as múltiplas modalidades semióticas (ou signos multimodais) nos processos comunicativos. Investigar como esses signos (tais como imagens, diagramas, gráficos, gestos, objetos, equações, linguagem oral ou escrita, entre outros) interagem na construção einterpretação de significados no discurso pode trazer importantes contribuições no que diz respeito ao ensino de ciências. No caso das simulações computacionais, como a que utilizamos, por exemplo, vários desses signos estão envolvidos. Estudos que analisem esses signos atuando de modo articulado podem auxiliar os pesquisadores na área nas investigações sobre os processos de apropriação e recontextualização de conceitos científicos por parte dos estudantes. 


\section{Agradecimentos}

Os autores agradecem ao Conselho Nacional de Desenvolvimento Científico e Tecnológico (CNPq) pelo apoio financeiro recebido na etapa de desenvolvimento do software. O primeiro autor agradece o apoio do Instituto Federal de Educação, Ciência e Tecnologia do Rio Grande do Sul e à Coordenação de Aperfeiçoamento de Pessoal de Nível Superior pela concessão da bolsa de estudos.

\section{Referências}

Allen, L., Beijersbergen, M. W., Spreeuw, R. J. C., \& Woerdman, J. P. (1992). Orbital angular momentum of light and the transformation of Laguerre-Gaussian laser modes. Physical Review A, 45(11), 8185-8185. https://doi.org/10.1103/PhysRevA.45.8185

Aspect, A. (2006). One century of quantum revolutions. In V. Scarani (Ed.), Quantum physics, a first encounter: Interference, entanglement, and reality (pp. ix-xiv). Oxford, MS: Oxford University Press.

Aspect, A., Dalibard, J., \& Roger, G. (1982a). Experimental realization of EinsteinPodolsky-Rosen-Bohm gedankenexperiment: A new violation of Bell's inequalities. Physical Review Letters, 49(2), 91-94. https://doi.org/10.1103/PhysRevLett.49.91

Aspect, A., Dalibard, J., \& Roger, G. (1982b). Experimental test of Bell's inequalities using time-varying analyzers. Physical Review Letters, 49(25), 1804-1807. https://doi. org/10.1103/PhysRevLett.49.1804

Aspect, A., Grangier, P., \& Roger, G. (1981). Experimental test of realistic local theories via Bell's Theorem. Physical Review Letters, 47(7), 460-463. https://doi.org/10.1103/ PhysRevLett.47.460

Bakhtin, M. M. (1981). The dialogic imagination: four essays. Austin: University of Texas Press.

Bakhtin, M. M. (2009). Marxismo e Filosofia da Linguagem: problemas fundamentais do método sociológico na ciência da linguagem. 13 ed. São Paulo: Hucitec.

Bakhtin, M. M. (2011). Os gêneros do discurso. In M. M. Bakhtin (Ed.), Estética da Criação Verbal (6 ed., pp. 261-306). São Paulo, SP: WMF Martins Fontes.

Bell, J. S. (1964). On the Einstein-Podolsky-Rosen paradox. Physics, 1(3), 195-200.

Bell, J. S. (1966). On the problem of hidden variables in Quantum Mechanics. Reviews of Modern Physics, 38(3), 447-452. https://doi.org/10.1103/RevModPhys.38.447

Bell, J. S. (1981). Bertlmann's socks and the nature of reality. Journal de Physique Colloques, 42(C2), 41-62. https://doi.org/10.1051/jphyscol:1981202

Beth, R. A. (1936). Mechanical detection and measurement of the angular momentum of light. Physical Review, 50(2), 115-115. https://doi.org/10.1103/PhysRev.50.115 
Bohm, D. (1952a). A suggested interpretation of the quantum theory in terms of "hidden" variables I. Physical Review, 85(2), 166-179. https://doi.org/10.1103/PhysRev.85.166

Bohm, D. (1952b). A suggested interpretation of the quantum theory in terms of "hidden" variables II. Physical Review, 85(2), 180-193. https://doi.org/10.1103/PhysRev.85.180

Bohm, D. (1989). Quantum theory. New York: Dover Publications.

Bohr, N. (1935). Can quantum-mechanical description of physical reality be considered complete? Physical Review, 48(8), 696-702. https://doi.org/10.1103/PhysRev.48.696

Chaiklin, S. (2003). The Zone of Proximal Development in Vygotsky's Analysis of Learning and Instruction. In A. Kozulin, B. Gindis, V. S. Ageyev, \& S. M. Miller (Eds.), Vygotsky's Educational Theory in Cultural Context (pp. 39-64). New York, NY: Cambridge University Press.

Clauser, J., Horne, M., Shimony, A., \& Holt, R. (1969). Proposed experiment to test local hidden-variable theories. Physical Review Letters, 23(15), 880-884. https://doi. org/10.1103/PhysRevLett.23.880

Dominguini, L., Maximiano, J. R., \& Cardoso, L. (2012). Novas abordagens do conteúdo Física Moderna no Ensino Médio público do Brasil. In IX Seminário de Pesquisa em Educação da Região Sul. Caxias do Sul, RS. Recuperado de http://www.ucs.br/etc/ conferencias/index.php/anpedsul/9anpedsul/paper/viewFile/653/534

Edamatsu, K. (2007). Entangled photons: generation, observation, and characterization. Japanese Journal of Applied Physics, 46(11), 7175-7187. https://doi.org/10.1143/ JJAP.46.7175

Einstein, A., Podolsky, B., \& Rosen, N. (1935). Can be Quantum-Mechanical description of physical reality be considered complete? Physical Review, 47(10), 777-780. https:// doi.org/10.1103/PhysRev.47.777

Feynman, R. P., Leighton, R. B., \& Sands, M. (1963). The Feynman lectures on Physics: quantum mechanics (Vol. 3). New York: Addison-Wesley.

Freedman, S. J., \& Clauser, J. F. (1972). Experimental test of local hidden-variable theories. Physical Review Letters, 28(14), 938-941. https://doi.org/10.1103/PhysRevLett.28.938

Freire Jr, O. (2006). Philosophy enters the optics laboratory: Bell's theorem and its first experimental tests (1965-1982). Studies in History and Philosophy of Science Part B: Studies In History and Philosophy of Modern Physics, 37(4), 577-616. https://doi. org/10.1016/j.shpsb.2005.12.003

Freire Jr., O. (2015). The quantum dissidentes: rebuilding the foundations of quantum mechanics (1950-1990). New York: Springer. 
Freire Jr., O., Carvalho Neto, R. A., Rocha, J. F. M., Vasconcelos, M. J. L., Socorro, M. S., \& Anjos, E. L. (1995). Introducing Quantum Physics in Secondary School. In Third International History, Philosophy and Science Teaching Conference (412-419), Minneapolis, MN.

Gori, F., Santarsiero, M., Borghi, R., \& Guattari, G. (1998). Orbital angular momentum of light: a simple view. European Journal of Physics, 19(5), 439-444. https://doi. org/10.1088/0143-0807/19/5/005

Greenberger, D. M., Horne, M. A., Shimony, A., \& Zeilinger, A. (1990). Bell's theorem without inequalities. American Journal of Physics, 58(12), 1131-1143. https://doi. org/10.1119/1.16243

Greenstein, G., \& Zajonc, A. (2006). The quantum challenge: modern research on the foundations of quantum mechanics. Sudbury: Jones and Bartlett.

Gröblacher, S., Paterek, T., Kaltenbaek, R., Brukner, C., Zukowski, M., Aspelmeyer, M., \& Zeilinger, A. (2007). An experimental test of non-local realism. Nature, (446), 871875. https://doi.org/10.1038/nature05677

Jacobs, K., \& Wiseman, H. M. (2005). An entangled web of crime: Bell's Theorem as a short story. American Journal of Physics, 73(10), 932-937. https://doi.org/10.1119/1.1979499

Jennewein, T., Simon, C., Weihs, G., Weinfurter, H., \& Zeilinger, A. (2000). Quantum cryptography with entangled photons. Physical Review Letters, 84(20), 4729-4732. https://doi.org/10.1103/PhysRevLett.84.4729

Johansson, A., Andersson, S., Salminen-Karlsson, M., \& Elmgren, M. (2016). "Shut up and calculate": the available discursive positions in quantum physics courses. Cultural Studies of Science Education. https://doi.org/10.1007/s11422-016-9742-8

Kozulin, A. (2008). A literary model for psychology. In D. Hicks (Ed.), Discourse, learning, and schooling (pp. 145-164). New York, NY: Cambridge University Press.

Kwiat, P. G., Waks, E., White, A. G., Appelbaum, I., \& Eberhard, P. H. (1999). Ultrabright source of polarization-entangled photons. Physical Review A, 60(2), R773-R776. https:// doi.org/10.1103/PhysRevA.60.R773

Leach, J., Padgett, M. J., Barnett, S. M., Franke-Arnold, S., \& Courtial, J. (2002). Measuring the orbital angular momentum of a single photon. Physical Review Letters, 88(25), 257901-257901. https://doi.org/10.1103/PhysRevLett.88.257901

Lemke, J. L. (1990). Talking Science: Language, Learning, and Values. Norwood: Ablex Publishing Corporation.

Lemke, J. L. (1992). Intertextuality and educational research. Linguistics and Education, 4(3-4), 257-267. https://doi.org/10.1016/0898-5898(92)90003-F

Loepp, S., \& Wootters, W. K. (2006). Protecting information: from classical error correction to quantum cryptography. Cambridge: Cambridge University Press. 
Martins, V. R. (2015). O ensino de Física Moderna nos livros didáticos do início do século $X X$. (Dissertação de Mestrado em Ensino de Ciências). Instituto de Física, Instituto de Química, Instituto de Biociências, Faculdade de Educação da Universidade de São Paulo, São Paulo.

Mermin, N. D. (1981). Bringing home the atomic world: Quantum mysteries for anybody. American Journal of Physics, 49(10), 940-943. https://doi.org/10.1119/1.12594

Neto, J. S., Cavalcanti, C. J. H., \& Ostermann, F. (2014). Apropriação do conceito de emaranhamento quântico por professores em formação. In XV Encontro de Pesquisa em Ensino de Física. São Sebastião, SP. Recuperado de http://www.sbf1.sbfisica.org.br/ eventos/epef/xv/sys/resumos/T0144-1.pdf

Netto, J. S. (2015). Complementaridade onda-partícula e emaranhamento quântico na formação de professores de Física segundo a perspectiva sociocultural. (Tese de Doutorado em Ensino de Física). Instituto de Física da Universidade Federal do Rio Grande do Sul, Porto Alegre.

Netto, J. S., Cavalcanti, C. J. H., \& Ostermann, F. (2015). Estratégias discursivas adotadas por professores em formação na compreensão do fenômeno da complementaridade em atividades didáticas mediadas pelo interferômetro virtual de Mach-Zehnder. Revista Brasileira de Pesquisa em Educação em Ciências, 15(2), 293-320.

Nussenzveig, H. M. (2014). Curso de Fisica básica (Vol. 4). 2. ed. São Paulo: Blücher.

Oliveira, I. S., Souza, A. M., Sarthour, R. S., Reis, M. S., \& Soares-Pinto, D. O. (2008). Emaranhamento: um recurso computacional que desafia os físicos. Ciência Hoje, 42(249), 32-37.

Ostermann, F. (1999). Um texto para professores do ensino médio sobre partículas elementares. Revista Brasileira de Ensino de Física, 21(3), 415-436.

Ostermann, F., \& Cavalcanti, C. J. H. (1999). Física Moderna e Contemporânea no Ensino Médio: elaboração de material didático, em forma de pôster, sobre partículas elementares e interações fundamentais. Caderno Catarinense de Ensino de Física, 16(3), 267-286.

Ostermann F., \& Moreira, M. A. (2000). Física Contemporánea en la escuela secundaria: una experiencia en el aula involucrando formación de profesores. Enseñanza de las Ciencias, 18(3), 391-404.

Ostermann, F., \& Prado, S. D. (2005). Interpretações da mecânica quântica em um interferômetro virtual de Mach-Zehnder. Revista Brasileira de Ensino de Física, 27(2), 193-203.

Pinto, A. C., \& Zanetic, J. (1999). É possível levar a Física Quântica para o Ensino Médio? Caderno Catarinense de Ensino de Física, 16(1), 7-34. 
Rigolin, G., \& Rieznik, A. A. (2005). Introdução à criptografia quântica. Revista Brasileira de Ensino de Física, 27(4), 517-526. https://doi.org/10.1590/S1806-11172005000400004 Rowe, M. A., Kielpinski, D., Meyer, V., Sackett, C. A., Itano, W. M., Monroe, C., \& Wineland, D. J. (2001). Experimental violation of a Bell's inequality with efficient detection. Nature, 409, 791-794. https://doi.org/10.1038/35057215

Santos, W. L. P., \& Mortimer, E. F. M. (2000). Uma análise de pressupostos teóricos da abordagem C-T-S (Ciência - Tecnologia - Sociedade) no contexto da educação brasileira. Ensaio Pesquisa em Educação em Ciências, 2(2), 1-23. https://doi.org/10.1590/198321172000020202

Sawyer, R. K., \& Berson, S. (2004). Study group discourse: how external representations affect collaborative conversation. Linguistics and Education, 15(4), 387-412. https://doi. org/10.1016/j.linged.2005.03.002

Terrazzan, E. A. (1992). A inserção da Física Moderna e Contemporânea no Ensino de Física na Escola de 2 Grau. Caderno Catarinense de Ensino de Física, 9(3), 209-214.

Terrazzan, E. A. (1994). Perspectivas para a inserção da Física Moderna na escola média. (Tese de Doutorado em Educação). Faculdade de Educação da Universidade de São Paulo, São Paulo.

Taddei, M. M., Escher, B. M., Davidovich, L., \& de Matos Filho, R. L. (2013). Quantum speed limit for physical processes. Physical Review Letters, 110(5), 1-5. https://doi. org/10.1103/PhysRevLett.110.050402

Volochinov, V. N. (1976). Discurso na vida e na arte: sobre a poética sociológica. In V. N. Volochinov (Ed.), Freudism. New York, NY: Academic Press.

Vygotsky, L. S. (1994). A formação social da mente. 5. ed. São Paulo: Martins Fontes.

Walther, P., Resch, K. J., Rudolph, T., Schenck, E., Weinfurter, H., Vedral, V., ... Zeilinger, A. (2005). Experimental one-way quantum computing. Nature, 434, 169-176. https:// doi.org/10.1038/nature03347

Weihs, G., Jennewein, T., Simon, C., Weinfurter, H., \& Zeilinger, A. (1998). Violation of Bell's inequality under strict Einstein locality conditions. Physical Review Letters, 81(23), 5039-5043. https://doi.org/10.1103/PhysRevLett.81.5039

Wertsch, J. V. (1984). The Zone of Proximal Development: some conceptual issues. In B. Rogoff \& J. V. Wertsch (Eds.), Children's learning in the "Zone of Proximal Development" (Vol. 23, pp. 7-18). San Francisco, CA: Jossey-Bass.

Wertsch, J. V. (1985). Vygotsky and the social formation of mind. Cambridge: Harvard University Press.

Wertsch, J. V. (1993). Voices of the mind: a sociocultural approach to mediated action. Cambridge: Harvard University Press. 
Wertsch, J. V. (1998). Mind as Action. New York: Oxford University Press.

Zeilinger, A. (2005). Novos experimentos, novas incertezas, novas questões. In A. Zeilinger (Ed.), A face oculta da natureza: o novo mundo da Física Quântica (pp. 57129). São Paulo, SP: Globo. 


\section{Apêndice}

\section{O emaranhamento visto como um dos fundamentos da teoria quântica}

Considerando um sistema de dois objetos quânticos, Einstein, Podolsky e Rosen propuseram um experimento mental que levava à constatação de que o formalismo matemático permitia a ocorrência de fenômenos não locais que contradiziam a hipótese da localidade. Isso foi fundamental para que argumentassem, no famoso artigo de 1935, que a descrição fornecida pela Mecânica Quântica, para esses fenômenos, era incompleta (Einstein et al., 1935). Para que a teoria oferecesse uma descrição completa da realidade física, era necessário admitir a existência de variáveis ocultas, consideradas como a única forma de evitar os efeitos radicalmente não locais que emergiam como resultados do experimento mental proposto, configurando-se assim o paradoxo EPR (Greenstein, \& Zajonc, 2006).

Em uma descrição moderna e simplificada do fenômeno do emaranhamento, considere dois objetos quânticos, 1 e 2, que estão correlacionados e num dado momento são levados para longe um do outro (pelo dispositivo experimental). $\mathrm{O}$ formalismo da FQ permite descrever o estado quântico desse sistema com dois objetos quânticos em termos de uma superposição dos vários estados possíveis desse sistema e a medição permitirá obter os autovalores associados a cada um desses estados do sistema. Suponha que os estados possíveis para cada objeto quântico sejam dois, denominados $|\alpha\rangle$ e $|\beta\rangle$, e que o vetor de estado do sistema emaranhado seja descrito pela superposição linear $|\psi\rangle_{12}=(1 / \sqrt{2})\left(|\alpha\rangle_{1} \otimes|\beta\rangle_{2}+|\alpha\rangle_{2} \otimes|\beta\rangle_{1}\right)$. Assim, se uma medição no objeto 1 resulta num autovalor $\alpha$ (correspondendo ao estado $|\alpha\rangle$ ), invocando o critério ${ }^{10}$ estabelecido por EPR, pode-se dizer que o objeto 2 está, com certeza, no estado $|\beta\rangle$. Nesse caso, esta informação é obtida de forma indireta, pois não houve de fato uma medição sobre o objeto 2. Essa redução de estado, decorrente da medição em um dos dois objetos quânticos correlacionados, define instantaneamente o estado do outro (não importando a distância entre ambos), e está prevista no próprio corpo teórico da teoria quântica (no formalismo matemático e por meio do postulado da superposição), consistindo em um fenômeno contraintuitivo e fortemente não local. Evidentemente, a propagação de informação, de forma que um objeto assuma instantaneamente um estado em termos de uma medida feita sobre o outro objeto distante, não seria aceitável sob o ponto de vista da Teoria da Relatividade Especial.

Os defensores da Escola de Copenhagen perceberam a ameaça que o paradoxo EPR representava e responderam imediatamente às afirmações de Einstein, Podolsky e Rosen. No volume seguinte do mesmo periódico onde o paradoxo EPR foi publicado, Bohr publicou um artigo com o mesmo título daquele que ameaçava sua teoria (Bohr, 1935). Ao mesmo tempo em que atacou o paradoxo EPR, argumentando em relação à

10 Segundo EPR, uma condição suficiente para a realidade de uma quantidade física é a possibilidade de predizêla com certeza, sem perturbar o sistema. 
ambiguidade do mesmo, Bohr defendeu o Princípio da Complementaridade afirmando que não havia quaisquer inconsistências na descrição que esta possibilitava, pois satisfazia todas as exigências racionais de completude. Na perspectiva de Bohr, o paradoxo EPR não continha nenhum desafio de ordem prática para a aplicação da teoria quântica a problemas físicos reais.

Anos se passaram entre os trabalhos de Bohm (1952a, 1952b, 1989), referentes à variáveis ocultas, para que Bell $(1964,1966)$ revisitasse o paradoxo EPR. Ele propôs um teorema (teorema de Bell), que consistia de um conjunto de desigualdades que, quando violadas, levavam à constatação de que as teorias de variáveis ocultas locais não podem descrever os sistemas quânticos. A teoria quântica violava tais desigualdades, como ficou claro anos mais tarde.

O trabalho de Bell teve uma repercussão inicial muito discreta, até que um grupo

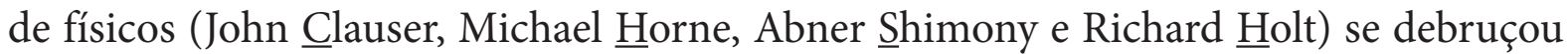
sobre este e acabou propondo uma desigualdade derivada desse teorema, conhecida como CHSH (Clauser, Horne, Shimony, \& Holt, 1969), que poderia ser testada em laboratórios de óptica quântica (Freire Jr, 2006). As primeiras medições a fim de testar as desigualdades de Bell foram realizadas por Freedman e Clauser a partir de uma transição entre estados de um átomo de cálcio, que resultava na emissão de dois fótons (Freedman, \& Clauser, 1972). Apesar de esses fótons serem emitidos com a mesma polarização, esta não era bem definida individualmente. A série dos três trabalhos do grupo de Alain Aspect (Aspect, Grangier, \& Roger, 1981; Aspect, Dalibard, \& Roger, 1982a, 1982b) refinou significativamente medidas anteriores e mostrou que as desigualdades de Bell eram violadas pela FQ, impondo sérias restrições à possibilidade de existência de teorias locais de variáveis ocultas que pudessem descrever os sistemas quânticos.

Experiências com sistemas de dois estados têm sido realizadas a partir da geração, em cristais não lineares, de pares de fótons emaranhados em estados de polarização (Weihs, Jennewein, Simon, Weinfurter, \& Zeilinger, 1998), com íons individuais aprisionados que estão emaranhados em estados de spin (Rowe et al., 2001) ou ainda, com sistemas de três estados, como (Greenberger, Horne, Shimony, \& Zeilinger, 1990) que demonstraram o teorema de Bell sem desigualdades a partir de sistemas de três partículas correlacionadas. Assim como ocorreu em relação à dualidade onda-partícula - considerada segundo Alain Aspect como a primeira revolução quântica (Aspect, 2006), a FQ revelava novamente o caráter enigmático e completamente não intuitivo dessa teoria física. Isso implicou a percepção de que esse fenômeno exótico era 'um novo mistério’ que não poderia ser reduzido à dualidade onda-partícula, configurando-se como o segundo aspecto fundamental da FQ, deflagrando a segunda revolução quântica (Aspect, 2006).

Mais recentemente, Gröblacher et al. (2007) demostraram experimentalmente que uma ampla classe de teorias realistas não locais são incompatíveis com correlações quânticas observáveis e isso "sugere que desistir do conceito de localidade não é suficiente para ser coerente com experimentos quânticos, a menos que certas funcionalidades 
intuitivas de realismo sejam abandonadas" (p. 871).

No caso da simulação computacional no IVMZ, o par emaranhado é produzido ${ }^{11}$ de forma que os fótons, aqui rotulados pelos índices 1 e 2, tenham a mesma polarização, podendo esta ser horizontal ou vertical - cada um desses estados do par tem probabilidade $1 / 2$. O estado emaranhado em polarização pela conversão paramétrica descendente do tipo I pode criar estados em configurações do tipo $(1 / \sqrt{2})\left(|\mathrm{h}\rangle_{1} \otimes|\mathrm{h}\rangle_{2}+\mathrm{e}^{\mathrm{i} \varphi}|\mathrm{v}\rangle_{1} \otimes|\mathrm{v}\rangle_{2}\right)$. A fase $\varphi$ pode ser facilmente controlada no experimento para que se tenha $\varphi=0$, de forma que o estado de polarização do par emaranhado seja $(1 / \sqrt{2})\left(|\mathrm{h}\rangle_{1} \otimes|\mathrm{h}\rangle_{2}+|\mathrm{v}\rangle_{1} \otimes|\mathrm{v}\rangle_{2}\right)$ (Kwiat, Waks, White, Appelbaum, \& Eberhard, 1999; Edamatsu, 2007). Os estados $|\mathrm{h}\rangle$ e $|v\rangle$ representam, respectivamente, estados de polarização do fóton para os quais é estabelecida uma correspondência com a oscilação do campo elétrico nas direções horizontal e vertical (que definem a polarização linear de uma onda eletromagnética - ver Figura 3). Para a simulação no software, foi adotado o estado emaranhado em polarização mostrado na equação (1). O estado translacional do par é tal que um fóton é direcionado para o caminho $A$ (associado ao estado translacional $\left|\mathrm{s}_{\mathrm{x}}\right\rangle$ ) e o outro para o braço B (associado ao estado translacional $\left|\mathrm{s}_{\mathrm{y}}\right\rangle$ ), como mostra o segundo termo entre colchetes na equação (1) - por exemplo, o primeiro termo $\left|s_{x}\right\rangle_{1} \otimes\left|s_{y}\right\rangle_{2}$ indica o fóton 1 associado ao caminho A e o fóton 2 ao B. O estado que descreve o par de fótons produzido após a interação com o cristal não linear, conforme discutido em Netto (2015, pp. 60-61), é

$$
|\psi\rangle_{12}=\left[\frac{1}{\sqrt{2}}\left(\left|\mathrm{~s}_{\mathrm{x}}\right\rangle_{1} \otimes\left|\mathrm{s}_{\mathrm{y}}\right\rangle_{2}+\left|\mathrm{s}_{\mathrm{x}}\right\rangle_{2} \otimes\left|\mathrm{s}_{\mathrm{y}}\right\rangle_{1}\right)\right] \otimes\left[\frac{1}{\sqrt{2}}\left(|\mathrm{~h}\rangle_{1} \otimes|\mathrm{h}\rangle_{2}+|\mathrm{v}\rangle_{1} \otimes|\mathrm{v}\rangle_{2}\right)\right]
$$

Note que o vetor de estado translacional é simétrico pelo fato de fótons serem bósons. Assim, o vetor de estado global também é simétrico. O símbolo de produto externo $\otimes$ em (1) deve obrigatoriamente ser usado, pois os espaços de Hilbert dos vetores de estado translacionais e de polarização são distintos, sendo também distintos os espaços de Hilbert dos vetores de estado de cada fóton. O polaroide representado na Figura 3 tem seu eixo de transmissão orientado segundo um ângulo $\xi_{i}$ com a direção horizontal. Se o estado de polarização do fóton corresponder ao análogo clássico de uma onda cujo campo elétrico oscila em uma direção $\theta$ em relação à horizontal, haverá uma probabilidade $\cos ^{2}\left(\xi_{i}-\theta\right)$ desse fóton ser (completamente) transmitido pelo polaroide e, consequentemente, $\operatorname{sen}^{2}\left(\xi_{i}-\theta\right)$ de ser absorvido pelo mesmo polaroide.

Classicamente, a polarização da luz descreve o comportamento do campo elétrico. Por exemplo, uma onda plano-polarizada (ou linearmente polarizada) na direção x indica que é nessa direção que o vetor campo elétrico oscila. Ao invés de se trabalhar

11 Esse processo de conversão de um fóton em um par de fótons emaranhados, conhecido como conversão paramétrica descendente de tipo I, se torna possível com a inserção de dois cristais não lineares (cristal PDC tipo-I, direcionador e compensador de fase) superpostos no interferômetro (Edamatsu, 2007). Nesse processo, o momentum linear é conservado e os fótons que formam o par apresentam uma pequena diferença de frequência entre si consequência da conservação do momentum). Esse cristal é representado pelo dispositivo em forma de ' $Y$ ' na Figura 2. 
com a descrição clássica da polarização, por meio do vetor campo elétrico, define-se o estado de polarização de cada fóton.

Sabemos que a luz pode transferir momentum angular aos objetos macroscópicos nos quais ela incide. Richard Beth demonstrou experimentalmente que luz circularmente polarizada exerce torque sobre os objetos, ou seja, transfere momentum angular (Beth, 1936). Além disso, sabe-se que o fóton pode possuir spin e momentum angular orbital (Leach, Padgett, Barnett, Franke-Arnold, \& Courtial, 2002), sendo o primeiro associado à polarização e o segundo à distribuição espacial de intensidade (Allen, Beijersbergen, Spreeuw, \& Woerdman, 1992; Gori, Santarsiero, Borghi, \& Guattari, 1998). Supondo que a luz incida em um objeto, se propague na direção $\mathrm{z}$, seja circularmente polarizada e que cada fóton absorvido transfira um quantum de momentum angular, pode-se mostrar que o momentum angular individual do fóton é bem definido ao longo da direção $\mathrm{z}$, assumindo os valores $J_{z}= \pm \hbar$. Os valores $-\hbar$ e $+\hbar$ correspondem, respectivamente, à luz polarizada circularmente à direita e à esquerda. Se a luz for linearmente polarizada mostra-se que não há transferência de momentum angular. Uma abordagem semiclássica dessa situação está bem desenvolvida em Nussenzveig (2014).

Partindo-se de (1) e representando-se adequadamente por operadores a ação dos polaroides no par emaranhado, pode-se mostrar que a probabilidade dos detectores A e B dispararem ao mesmo tempo (cada um acusa um fóton do par - o que se chama coincidência) após a interação com os polaroides é $p_{A B}=(1 / 2) \cos ^{2}\left(\xi_{A}-\xi_{B}\right)$ (Edamatsu, 2007, p. 7183), onde $\xi_{A}$ e $\xi_{B}$ são, respectivamente, os ângulos de orientação dos polaroides posicionados nos braços A e B (ver Figura 3). Pode-se mostrar também que a probabilidade $p_{A}$ de apenas o detector A disparar é $p_{A}=(1 / 2) \operatorname{sen}^{2}\left(\xi_{A}-\xi_{B}\right)$, sendo esta igual à probabilidade $p_{\mathrm{B}}$ de apenas o detector $\mathrm{B}$ disparar. Por fim, pode-se também mostrar que a probabilidade $p_{\text {abs }}$ do par ser absorvido pelos polaroides (e nenhum dos dois detectores disparar) é igual à $p_{\mathrm{AB}}$. Relembramos que na atual versão do software, apenas as coincidências são registradas. 


\section{Jader da Silva Netto}

http://orcid.org/0000-0002-1298-1796 Instituto Federal de Educação Ciência e Tecnologia do Rio Grande do Sul campus Bento Gonçalves Bento Gonçalves, Brasil jader.netto@bento.ifrs.edu.br

Cláudio José de Holanda Cavalcanti

() http://orcid.org/0000-0002-2477-3150 Universidade Federal do Rio Grande do Sul Instituto de Física, Departamento de Física Porto Alegre, Brasil claudio.cavalcanti@ufrgs.br

Fernanda Ostermann

http://orcid.org/0000-0002-0594-2174 Universidade Federal do Rio Grande do Sul Instituto de Física, Departamento de Física Porto Alegre, Brasil fernanda.ostermann@ufrgs.br

Submetido em 18 de Novembro de 2017 Aceito em 14 de Março de 2018 Publicado em 23 de Junho de 2018 